\title{
Dioscorea nipponica Makino: a systematic review on its ethnobotany, phytochemical and pharmacological profiles
}

Si-hong Ou-yang ${ }^{1}$, Tao Jiang ${ }^{2}$, Lin Zhu ${ }^{1 *}$ and Tao Yi ${ }^{*}$

\begin{abstract}
Dioscorea nipponica Makino is a perennial twining herbs belonging to the family Dioscoreaceae, which is mainly distributed in the northeastern, northern, eastern and central regions of China. Traditionally, the rhizome of this herb has been commonly used by Miao and Meng ethnic groups of China to treat rheumatoid arthritis, pain in the legs and lumbar area, Kashin Beck disease, bruises, sprains, chronic bronchitis, cough and asthma. Modern pharmacological studies have discovered that this herb possesses anti-tumor, anti-inflammatory, anti-diuretic, analgesic, anti-tussive, panting-calming and phlegm-dispelling activities, along with enhancing immune function and improving cardiovascular health. In recent years, both fat-soluble and water-soluble steroidal saponins were isolated from the rhizomes of D. nipponica using silica gel column chromatography, thin layer chromatography and high performance liquid chromatography methods. Saponin and sapogenins are mainly responsible for most of the pharmacological effects of this plant. Further, the chemical components of the aboveground parts contain more than 10 kinds of phenanthrene derivatives. The present review summarizes the knowledge concerning the geographical distribution, chemical composition, pharmacological effects, toxicology studies and clinical applications of D. nipponica.
\end{abstract}

Keywords: Dioscorea nipponica Makino, Steroid saponins, Geographical distribution, Active ingredient, Pharmacological studies

\section{Introduction}

Dioscorea nipponica Makino is a species of the Dioscorea genus belonging to the family Dioscoreaceae. According to the traditional Chinese medicine, it is bitter-sweet in taste and warm in nature [1-7]. It mainly acts on liver, kidney and lungs, displaying anti-rheumatic, analgesic, blood circulation-stimulating, the lung channel-dredging, digestive, anti-diuretic, anti-tussive, panting-calming and phlegm-dispelling activities [2, 3, 5, 6]. Medicinally, it is commonly used for the treatment of rheumatoid arthritis, pain in the legs and lumbar area, Kashin-Beck disease, bruises, sprains, chronic bronchitis, cough and asthma $[2,5,6]$. In recent times, it has been used as an important industrial raw material for the synthesis of

\footnotetext{
*Correspondence: linzhu912@gmail.com; yitao@hkbu.edu.hk ${ }^{1}$ School of Chinese Medicine, Hong Kong Baptist University, Kowloon Tong, Hong Kong Special Administrative Region, China Full list of author information is available at the end of the article
}

steroid hormones and saponin drugs for coronary heart disease [2].

\section{Geographic distribution}

Dioscorea nipponica is a perennial twining herb, which grows in the north and central subtropical zones. It is distributed in the range of East longitude $105^{\circ} \sim 109^{\circ}$ to North latitude $26^{\circ} 34^{\prime} \sim 50^{\circ} 15^{\prime}$ [8], mainly in the northeastern, northern, eastern and the central regions of China, such as Shandong, Henan, Anhui, the north of Zhejiang, Jiangxi (Lushan), Shanxi (the north of Qinling), Gansu, Ningxia, the south of Qinghai, the northwest of Sichuan $[2,9,10]$, Heilongjiang, Jilin, Liaoning, Shanxi, Henan, Shanxi, Hubei, Gansu, Hunan, Jiangsu and Zhejiang (Fig. 1) [3, 9, 11, 12]. It is grown in Tianshui, Longnan, Pingliang, Qingyang, Dingxi, Gannan, Linxia [13] and also in the north of Honshu as well as Korea and eastern Russia [2]. Changbai Mountain in the northeastern China is one of the major distribution and resource supply areas 


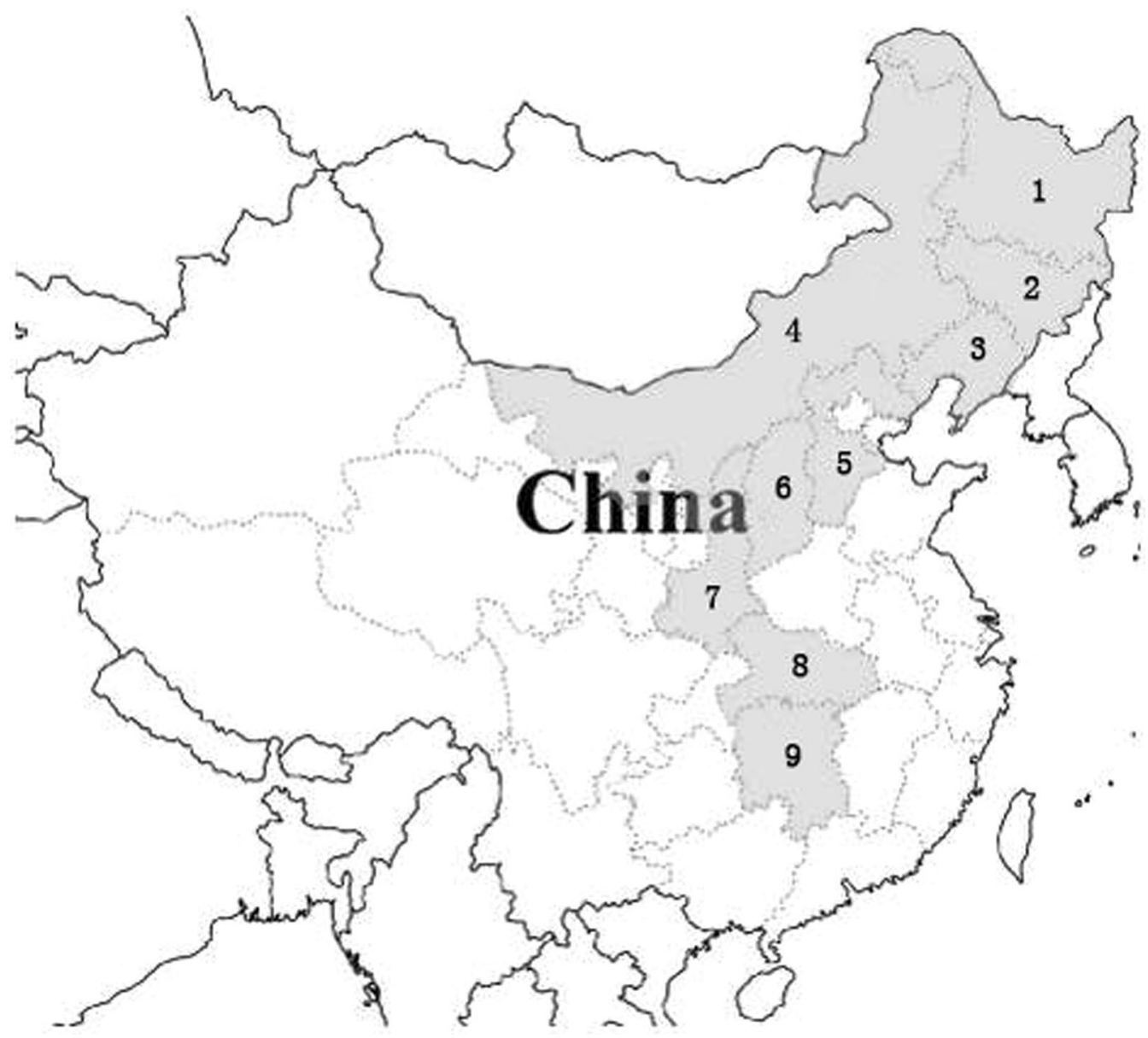

Fig. 1 Distribution of D. nipponica in China: (1) Heilongjiang, (2) Jilin, (3) Liaoning, (4) Neimenggu, (5) Hebei, (6) Shanxi, (7) Shanxi (the north of Qinling), (8) Hubei, and (9) Hunan provinces

of D. nipponica. In addition, the wild resources are scattered vertically at the altitude range of $100-1000 \mathrm{~m}$ in Korea, Japan, Russia and other countries $[8,14,15]$.

\section{Botanical description}

Dioscorea nipponica is a perennial twiner, whose length can reach up to $5 \mathrm{~m}$. The rhizome is horizontal, woody, highly branched, has a slightly curved cylindrical shape and its cross section appears white or yellowish-white with light brown vascular bundle dots [8]. In addition, its phellem layer is obviously detached and its tawny cortex falls off as flakes (Fig. 2) [16]. The aerial stem is slender, cylindrical, glabrescent with longitudinal grooves and twines to the left. The leaves are alternate simple, and palmate with a length of $10-15 \mathrm{~cm}$ and a width of 9-13 cm. The petiole length ranges from 10 to $20 \mathrm{~cm}$ while the leaf

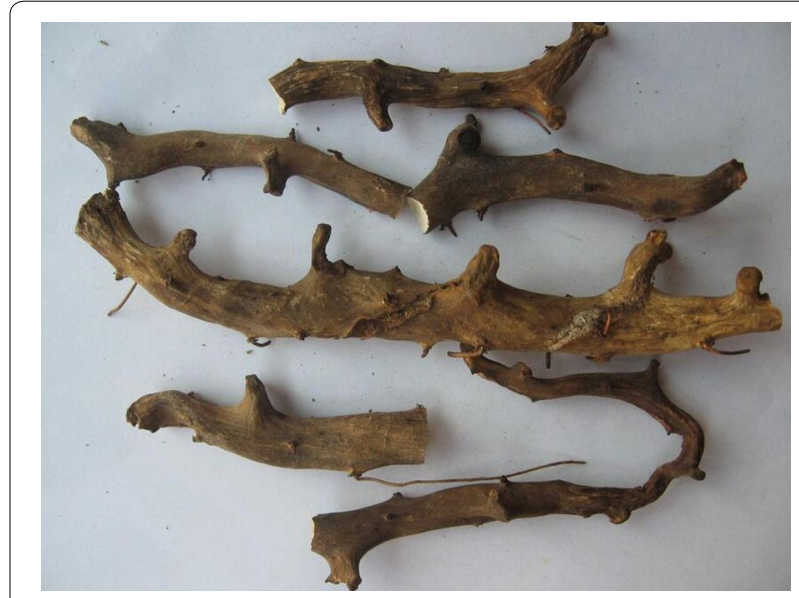

Fig. 2 Photos of the rhizomes of D. nipponica 


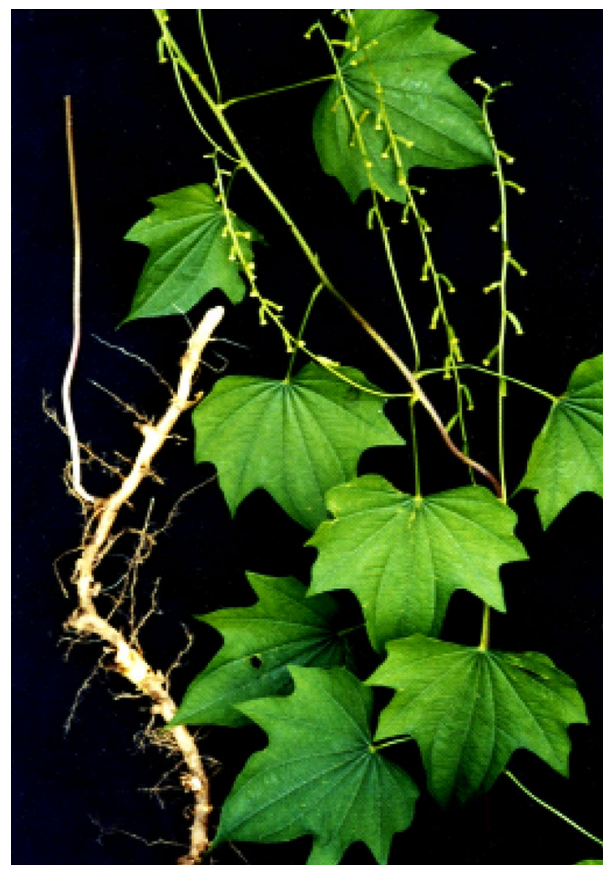

Fig. 3 Photo of the plant of D. nipponica

edge has an anisometric triangular shallow, medium or deep crack. The apex leaves are smaller, nearly entire, yellowish-green, shiny, glabrous or sparsely minutely setose, especially thick on the pulse (Fig. 3).

The flower of $D$. nipponica are unisexual, yellowishgreen and droop like a small bell. The plant is dioecious; the male inflorescence is an axillary compound spike usually composed of 2-4 integrated small flowers and has a simple flower with lanceolate bracts at the top. The saucer-shaped perianth is 6-cracked with obtuse apex lobes, while 6 stamens are inserted at the middle with inward anthers. The female inflorescence is spicate, solitary; perianth is 6-cracked with lanceolate lobes; stigma is 3-cracked and the lobes are 2-cracked [17, 18].

The mature dry capsules are yellow, obovate-elliptic and prismatic in shape with winged edges; with a usual length of about $2 \mathrm{~cm}$ and a width of $1.5 \mathrm{~cm}$. There are two rectangular seeds surrounded by rectangular wings in each locule inserted at the base of the axis, in which sometimes only one is fertile [19]. Moreover, the flowering period is from June to August and the fruiting stage is from August to October [20-24].

\section{Phytochemistry}

Du et al. [25] employed separation methods such as silica gel column chromatography, thin layer chromatography (TLC) and high performance liquid chromatography (HPLC) to characterize the chemical constituents of $D$. nipponica. The main bioactive compounds of $D$. nipponica are steroid saponins which can produce aglycones and sugars after hydrolysis. The structures of the aglycones are composed of three types of scaffolds: furostane, a pentacyclic ring system with a sixth open ring; spirostane, a hexacyclic ring system; and pregnane, a tetracyclic ring system. The sugar part is mainly composed of glucose and rhamnose in various proportions and linkages. The saponins of this plant mainly include both water-soluble and water-insoluble steroid saponins. The water-soluble saponins mainly include dioscin, gracillin and Trillium tschonoskii saponin. On the other hand, the content of diosgenin, the major steroid sapogenin, in D. nipponica is $1.5-2.6 \%$ [21]. In the water-insoluble saponins, the sugar part comprises of $3-O-\{\alpha$-L-rhamnopyranosyl- $(1 \rightarrow 2)-[\beta-\mathrm{D}-$ glucopyranosyl- $(1 \rightarrow 3)]\}-\beta-\mathrm{D}$-glucopyranoside; while the water-soluble ones possess $3-O-[\alpha-\mathrm{L}-$ rhamnopyranosyl- $(1 \rightarrow 3)-\alpha$-L-rhamnopyranosyl- $(1 \rightarrow 4)-\alpha$-Lrhamnopyranosyl- $(1 \rightarrow 4)]$ - $\beta$-D-glucopyranoside.

Li et al. [26] analyzed the saponin components by using the HPLC-ESI-MS/MS method and characterized five compounds including dioscoresides A, dioscoresides $\mathrm{C}$ and hypoglaucine A. By adopting the method of silica gel column chromatography, Kang et al. [27] separated new furan gonane saponins from the rhizome, namely, 26-O- $\beta$ D-glucopyranosyl-25(R)-22-hydroxy-furostanol- $\Delta 5(6)$-en$3 \beta$,26-dihydroxyl-3-O-\{ $\alpha$-L-rhamnopyranosyl- $(1 \rightarrow 2)-\alpha$-Lrhamnopyranosyl- $(1 \rightarrow 4)\}-\beta$-D-glucopyranoside and 26-O- $\beta$-D-glucopyranosyl-25(R)-22-hydroxyfurostanol- $\Delta 5(6)$-en-3 $\beta, 26$-dihydroxyl-3-O- $\{\alpha-\mathrm{L}$ rhamnopyranosyl- $(1 \rightarrow 2)-\alpha-\mathrm{L}-$ rhamnopyranosyl$(1 \rightarrow 3)\}$ - $\beta$-D-glucopyranoside.

Zhang et al. [28] carried out research on the watersoluble compounds of $D$. nipponica and identified 14 compounds, including 3 steroidal saponins, 3 phenolic glycosides, 2 dipeptides and 6 other classes of compounds. Shu et al. [29] separated 14 compounds, including 12 steroidal saponins and 2 diphenyl heptanes, among which, most of the steroidal saponins showed strong anti-tumor activity. Besides steroidal saponins, $D$. nipponica also contains water-soluble polysaccharides and other components. Wang et al. [30] extracted crude polysaccharides from this plant by applying the methods of hot water boiling and the ethyl alcohol precipitation. Li et al. [31] took the lead to separate an acidoid with strong anti-tussive effect from the water-soluble components, which is named as pair-acrinyl tartaric acid. Zhang et al. [32] identified at least eighteen amino acids in D. nipponica, and the total amino acid content accounts to $6.804 \%$.

\section{Roots and rhizomes}

Steroidal saponins are abundant in the roots and rhizomes of $D$. nipponica, where the following 
chemical compositions have been reported (Fig. 4): Dioscin (1) [9, 13, 33-47], gracillin (2) [9, 13, 33-36, 40, 42, 45-48], trillin (3) [9, 14, 36, 42, 44, 45, 49, 50], diosgenin-3- $O-[\alpha-\mathrm{L}-\mathrm{rhamnopyranosyl}-(1 \rightarrow 3)-\alpha-\mathrm{L}-$ $\mathrm{rh}$ a m no p y r a no syl - $\left(\begin{array}{lll}1 & \rightarrow & 4\end{array}\right)-\alpha-\mathrm{L}-$ rhamnopyranosyl-( $1 \rightarrow 4)]-\beta$-D-glucopyranoside $(4)[9,25$, $45]$, diosgenin-3-O-\{ $\alpha$-L-rhamnopyranosyl- $(1 \rightarrow 2)$ - $[\alpha$-Lrhamnopyranosyl-( $1 \rightarrow 3)]\}$ - $\beta$-D-glucopyranoside $[25,48,51]$, diosgenin $(6)[9,36,38,42,45-47,49,52]$, asperin $(7)[9,13,45], 25-\Delta$-spirosta-3,5-diene (8) [9, 13, $14,45-47,53,54]$, piscidic acid (9) [9, 13, 45-47, 55], $3 \beta, 26$-glycol-25(R)- $\Delta 5,20$ (22)-diene-furostanol-26- $O-\beta$ D-glucopyranoside $(\mathbf{1 0})[40,45,56]$, progenin II (11) [9, 48, 52], prosapogenin A of dioscin (12, progenin III) [9, 48], pseudo-protodioscin $(\mathbf{1 3})$ [9, 39, 40], protodioscin (14) $[9,36,39,40,42,48,52]$, protogracillin (15) $[9,36$, 40, 42, 45, 48], kikuba-saponin (16) [9], smilagenone (17) [45], and epistephanine (18) [45, 46]. In addition, allantoin, sterols, flavones, resins, polysaccharides and starch have also been identified as constituents in the roots of $D$. nipponica $[14,18]$.

\section{Aboveground parts}

The classes of chemical constituents occurring in the aboveground portion of D. nipponica are presented in Table 1 and the structures are shown in Fig. 5.

\section{Pharmacological activity}

The rhizomes of D. nipponica (Rhizoma Dioscorea nipponica (RDN)) are rich in the dioscin content. After the oral administration of dioscin, diosgenin produced from the metabolism of intestinal flora is the major true bioactive compound. As verified by modern research, RDN has various pharmacological activities such as improving the cardiovascular system, regulating immune function, preventing tumors, phlegm, cough and asthma, as well as relieving inflammation and pain [62].

\section{Effects on the cardiovascular system}

Dioscin can improve myocardial injuries, prevent the anti-oxygenation of myocardial cells, relieve the calcium overload of myocardial cells, and prevent the hypoxia of myocardium via different mechanisms [63].

Through the hypoxia/reoxygenation damage model of the neonatal rat in vitro cardiomyocyte culture, $\mathrm{Ni}$ et al. [64] compared the levels of superoxide dismutase (SOD), malondialdehyde (MDA) and nitric oxide (NO) in the control group, the hypoxia/reoxygenation injury group, and the dioscin groups $(10,30$, and $100 \mathrm{~mL} / \mathrm{L}$, respectively). In this context, dioscin significantly improved the in vitro SOD activity of myocardial cells after hypoxia/ reoxygenation and reduced the content of MDA and NO in a dose-dependent manner. This indicated that dioscin can play a protecting role in the hypoxia/reoxygenation of myocardial cells through the anti-oxygenation effect. Using a similar model, Gao et al. [65] concluded that the myocardial cell beat rate, cell survival rate, and mitochondrial membrane potential of the dioscin intervention group were significantly higher than those in the ischemia-reperfusion (I/R) group. Moreover, the average calcium-ion fluorescence intensity in cardiac cells was clearly lower than that of the I/R group.

Fan et al. [66] observed a significant decrease in the ATP and adenylic acid levels in the myocardium of I/R rats using the Reversed-phase HPLC (RP-HPLC) method. In this context, the I/R rats with dioscin intervention have shown an increase in the ATP and adenylic acid levels, which further improved the myocardial energy metabolism disorder.

The expression percentages of CD62P and CD63 in plasma were detected using flow cytometry (FCM) while the platelet-activating factor (PAF) levels were determined through enzyme-linked immunosorbent assay (ELISA) method by Wei et al. [67]. The myocardial I/R model of dioscin-pretreated rats were studied, which revealed a significant reduction in the cytokine content of platelet activation in plasma. Hence, it was inferred that the mechanism of anti-myocardial I/R might be related to the anti-platelet activation.

Ning et al. [68] have observed that diosgenin could significantly reduce the pathological expression and degree of myocardial ischemia, reduce myocardial infarction, dilate the coronary arteries, increase myocardial blood supply, and improve the function of vascular endothelial cells in the acute dog experimental myocardial ischemia model. Based on this work, the influence of diosgenin on the cardiac hemodynamics of dogs was studied [69] and the results indicated that the former can dilate the coronary vessels as well as effectively reduce the coronary resistance and heart load. Meanwhile, there was an increase in cardiac output, cardiac stroke volume, myocardial blood and oxygen supply, while the effective impact on the heart can be strengthened. In this way, it can play the role in regulating and improving the cardiovascular system and providing an experimental basis for the clinical treatment of ischemic heart disease. Subsequently, the same group [70] used the coronary artery ligation myocardial infarction model of rats to measure the myocardial infarction scope and vasoactive effect of diosgenin. The result demonstrated that diosgenin could significantly reduce the extent of myocardial infarction, inhibit the increase of serum creatine kinase (CK) and lactate dehydrogenase (LDH), decrease the elevated MDA levels, increase the SOD and NO levels, reduce the level of myocardial enzymes, and enhance the oxygen free radical scavenging capacity. 


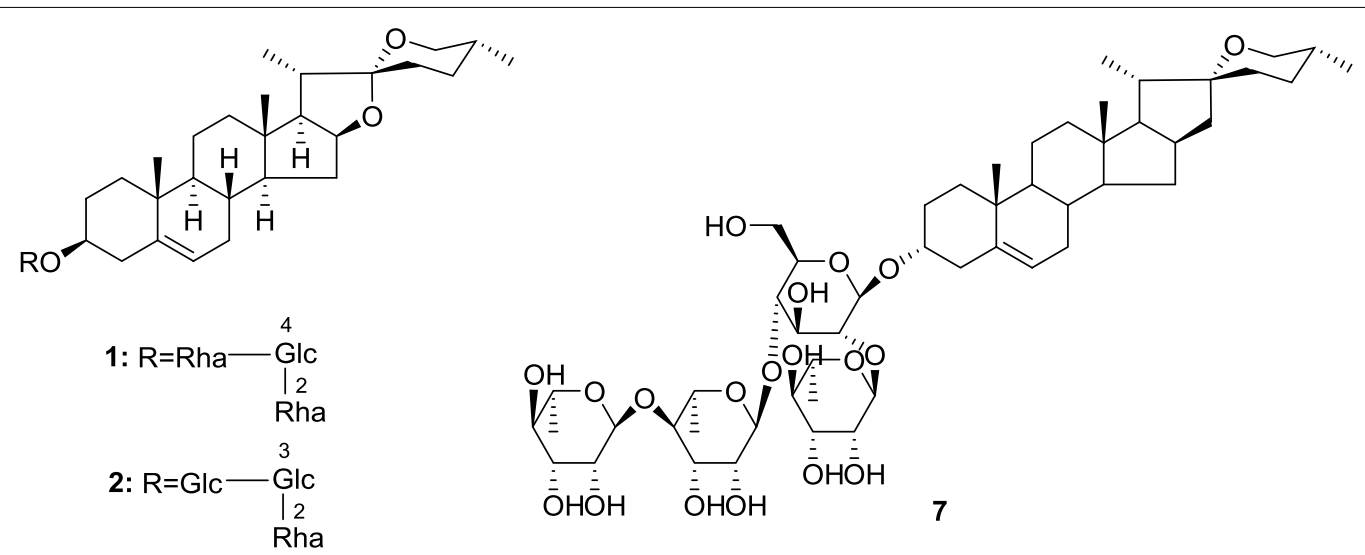

3: $R=G l c$

4: $\mathrm{R}=\mathrm{Glc}-\stackrel{4}{\mathrm{Rh} a-} \stackrel{4}{\mathrm{R} h a}$

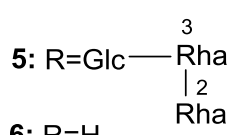

Rha
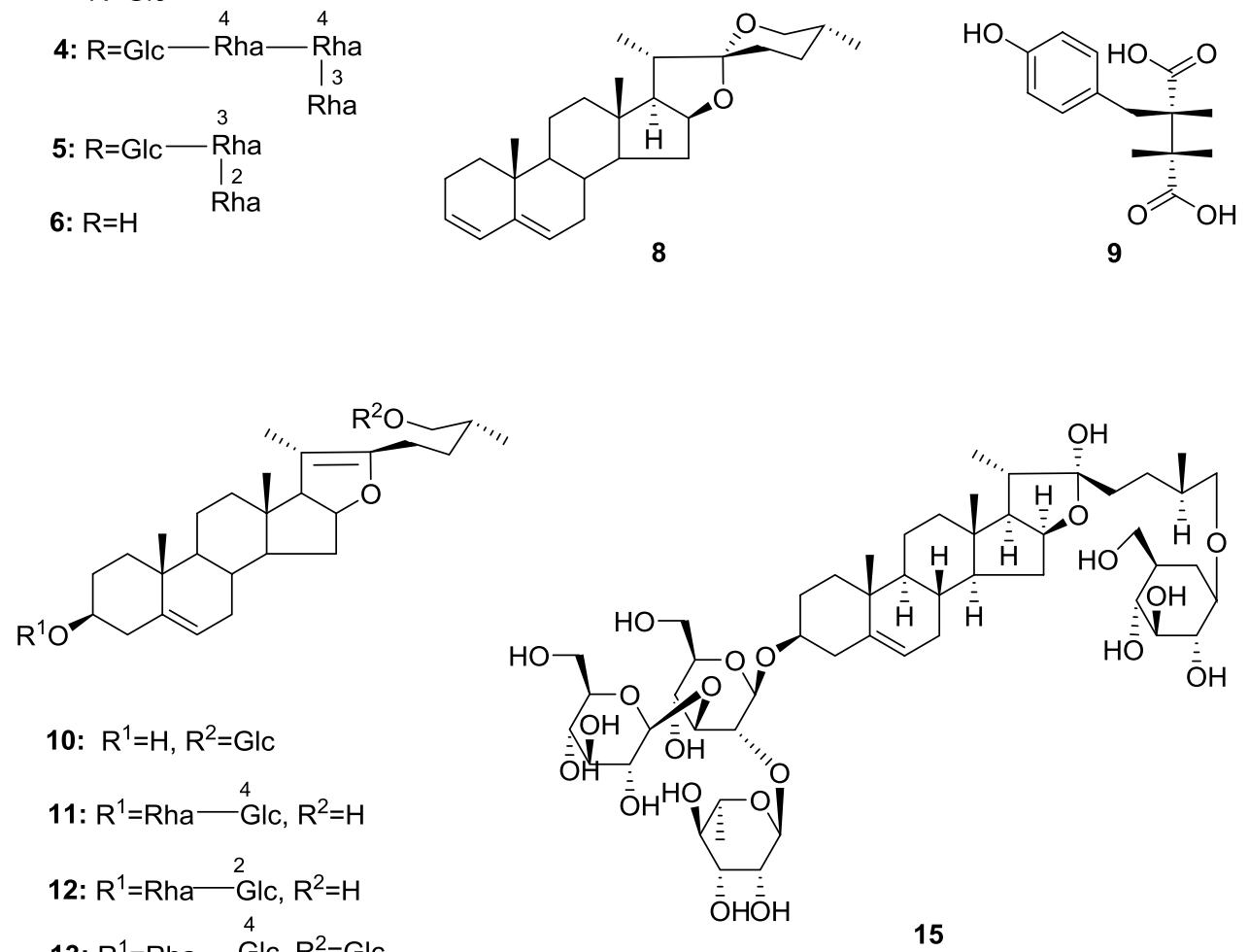

10: $\mathrm{R}^{1}=\mathrm{H}, \mathrm{R}^{2}=\mathrm{Glc}$

11: $\mathrm{R}^{1}=\mathrm{Rha}-\stackrel{4}{\mathrm{G}} \mathrm{lc}, \mathrm{R}^{2}=\mathrm{H}$

12: $\mathrm{R}^{1}=\mathrm{Rha}-{ }^{2} \mathrm{Glc}, \mathrm{R}^{2}=\mathrm{H}$

13: $R^{1}=$ Rha- -4 lc, $R^{2}=G l c$

15

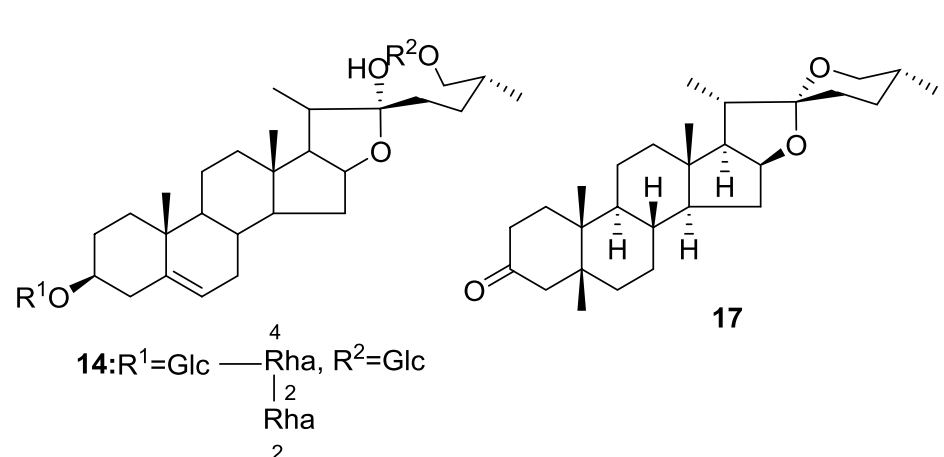

16: $\mathrm{R}^{1}=\mathrm{Glc}-\stackrel{2}{\mathrm{Rh} a, \mathrm{R}^{2}=\mathrm{Glc}}$

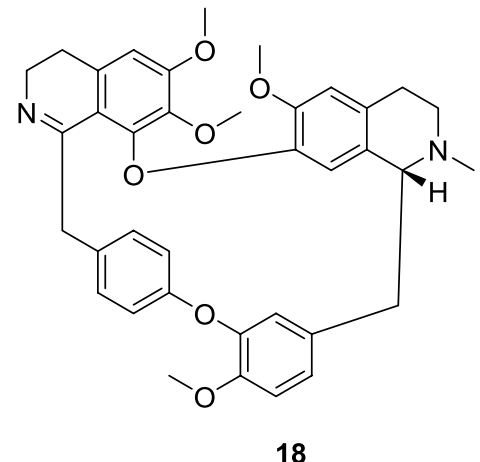

Fig. 4 Chemical composition of $D$. nipponica roots $(G \mid C=\beta$-D-glucopyranosyl, Rha $=\alpha$-L-rhamnopyranosyl) 
Table 1 The chemical constituents occurring in the aboveground portion of $D$. nipponica

\begin{tabular}{|c|c|c|}
\hline Class & Chemical compounds & Refs. \\
\hline \multirow[t]{8}{*}{ Phenanthrene-based compounds } & 4,6-Dihydroxy-2,3,7-trimethoxy-9,10-dihydrophenanthrene (19) & [57] \\
\hline & $\begin{array}{l}\text { 1-(4,7-Dihydroxy-2,6-dimethoxy-9,10-dihydrophenanthrenyl)-4,7-dihydroxy-2,6-dimethoxy- } \\
\text { 9,10-dihydrophenanthrene (20) }\end{array}$ & {$[57,58]$} \\
\hline & 7-Hydroxy-2,3,5-trimethoxy-9,10-dihydrophenanthrene (21) & [57] \\
\hline & 2,7-Dihydroxy-3,5-dimethoxy-9,10-dihydrophenanthrene (22, 6-methoxycoelonin) & {$[57,59]$} \\
\hline & 4,7-Dihydroxy-2,3,6-trimethoxyphenanthrene (23) & {$[57,60]$} \\
\hline & 3,7-Dihydroxy-2,4,6-trimethoxyphenanthrene (24) & [57] \\
\hline & 1-(2,7-Dihydroxy-4,6-dimethoxyphenanthrenyl)-2,7-dihydroxy-4,6-dimethoxyphenanthrene (25) & [57] \\
\hline & $\begin{array}{l}\text { 7-Hydroxy-2,6-dimethoxy-1,4-phenanthraquinone (26, dioscoreanone) } \\
\text { 2-ethoxy-7-hydroxy-6-methoxy-1,4-phenanthraquinone (27) }\end{array}$ & [57] \\
\hline \multirow[t]{8}{*}{ Phenols and organic acidic compounds } & 3',5-Dihydroxy-3,4'-dimethoxybibenzyl (28) & [57] \\
\hline & 4,4'-Dihydroxy-3,3'-dimethoxy-trans-stilbene (29) & {$[57,61]$} \\
\hline & 1,7-bis(4-Hydroxyphenyl)-1,4,6-heptatrien-3-one (30) & {$[57,59,61]$} \\
\hline & 1,7-bis(4-Hydroxyphenyl)-4,6-heptabien-3-one (31) & {$[57,61]$} \\
\hline & 3,4-Dihydroxybenzoic acid (32, protocatechuic acid) & {$[57,61]$} \\
\hline & 4-Hydroxy-3-methoxybenzoic acid (33, vanillic acid) & {$[57,61]$} \\
\hline & 4-Hydroxybenzoic acid (34) & {$[57,61]$} \\
\hline & Pyrocatechol (35) & {$[57,61]$} \\
\hline Coumarins & (35)-6,8-dihydroxy-3-phenyl-3,4-dihydroisocoumarin (36, montroumarin) & {$[57,58]$} \\
\hline \multirow[t]{4}{*}{ Flavonoids } & Kaempferol (37) & {$[57,61]$} \\
\hline & Kaempferol-3-O- $\beta$-D-glucopyranoside (38) & {$[57,58]$} \\
\hline & Kaempferol-3-O- $\beta$-rutinoside (39) & {$[57,58]$} \\
\hline & Quercetin-3-O-rutinoside (40, rutin) & {$[57,61]$} \\
\hline Glycosides & 4-Hydroxyphenethyl-ol-4-O- $\beta$-D-glucopyranoside (41, icariside D2) & {$[57,61]$} \\
\hline Steroids & Daucosterol (42) & {$[57,58]$} \\
\hline Polyols & D-Mannitol (43) & {$[57,58]$} \\
\hline
\end{tabular}

Zhang et al. [71] used the ${ }^{86} \mathrm{Rb}$ trace method to observe the impact of RDN saponins on the myocardial blood flow of rats. The results showed that the ${ }^{86} \mathrm{Rb}$ myocardial intake ability of rats has been increased by $9.46 \%$ for the $225 \mathrm{mg} / \mathrm{kg}$ group ( $\mathrm{P}<0.05), 18.46 \%$ for the $337.5 \mathrm{mg} /$ $\mathrm{kg}$ group $(\mathrm{P}<0.05)$, and $31.47 \%$ for the $675 \mathrm{mg} / \mathrm{kg}$ group $(\mathrm{P}<0.01)$. This indicated that the perhexiline of RDN and the water-soluble saponins can significantly increase the myocardial blood flow, relieve myocardial anoxia, and promote the treatment of coronary heart disease as well as angina.

\section{Regulating the immune function}

Gao et al. [72] used sheep red blood cell (SRBC) hemolysin antibodies to generate the dinitrofluorobenzene (2,4-DNFB)-induced delayed-type hypersensitivity test model in mice in order to observe the impact of $D$. nipponica on the cellular immune function. The result showed that intragastric administration $(1 \mathrm{~g} / \mathrm{kg})$ of total saponins of Rhizoma Dioscoreae nipponica (TSRDN) could significantly reduce the generation of SRBC hemolysin antibody in mice compared with the prednisone
$(2 \mathrm{mg} / \mathrm{kg})$ group $(\mathrm{P}<0.05)$. Further, TSRDN inhibited the generation of SRBC hemolysin antibodies of mice and the delayed-type hypersensitivity caused by DNFB, which suggests its significant role in inhibiting the humoral immunity and cellular immune function.

Nan et al. [73] used the decoction of RDN to feed the mice for 7 days, which caused the atrophy of thymus $(\mathrm{P}<0.01)$. Moreover, the positive rate of nonspecific acid esterase (ANAE) was reduced $(\mathrm{P}<0.05)$, the delayed type hypersensitivity of skin was inhibited $(\mathrm{P}<0.01)$, the formation of serum hemolysin was decreased $(P<0.01)$, the chicken erythrocyte cytophagy percentage by the mice enterocoelia cell and the phagocytic index were increased, and the enzyme content of serum bacteriolysis has increased as well. On the contrary, the impact on the spleen weight and structure was insignificant $(\mathrm{P}<0.05)$. Thus, they concluded that RDN could inhibit both cellular and humoral immunity, but enhance the phagocytosis of macrophages.

Song et al. [74] used the alcohol extract of RDN on mice: At a low dose of RDN $(1.25 \mathrm{mg} / \mathrm{mL})$, the concanavalin A (ConA)-induced splenocyte proliferation of mice 


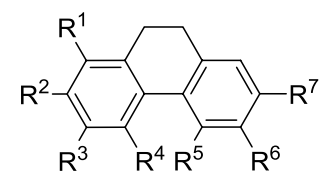

19: $\mathrm{R}^{1}=\mathrm{H}, \mathrm{R}^{2}=\mathrm{OCH}_{3}, \mathrm{R}^{3}=\mathrm{OCH}_{3}, \mathrm{R}^{4=} \mathrm{OH}, \mathrm{R}^{5}=\mathrm{H}, \mathrm{R}^{6}=\mathrm{OH}, \mathrm{R}^{7}=\mathrm{OCH}_{3}$

20: $\mathrm{R}^{1}=\mathrm{H}_{3} \mathrm{CO}$

21: $R^{1}=\mathrm{H}, \mathrm{R}^{2}=\mathrm{OCH}_{3}, \mathrm{R}^{3}=\mathrm{OCH}_{3}, \mathrm{R}^{4}=\mathrm{H}, \mathrm{R}^{5}=\mathrm{OCH}_{3}, \mathrm{R}^{6}=\mathrm{H}, \mathrm{R}^{7}=\mathrm{OH}$

22: $R^{1}=H, \quad R^{2}=\mathrm{OH}, R^{3}=\mathrm{OCH}_{3}, \mathrm{R}^{4}=\mathrm{H}, \mathrm{R}^{5}=\mathrm{OCH}_{3}, \mathrm{R}^{6}=\mathrm{H}, \mathrm{R}^{7}=\mathrm{OH}$

23: $R^{1}=H, R^{2}=\mathrm{OH}, \mathrm{R}^{3}=\mathrm{OCH}_{3}, \mathrm{R}^{4}=\mathrm{OH}, \mathrm{R}^{5}=\mathrm{H}, \mathrm{R}^{6}=\mathrm{OCH}_{3}, \mathrm{R}^{7}=\mathrm{OH}$<smiles>COc1cc2c(ccc3cc(OC)c(O)c(OC)c32)cc1O</smiles>

24<smiles>CCOC1=CC(=O)c2c(ccc3cc(O)c(OC)cc23)C1=O</smiles>

27<smiles>COc1cc2c(ccc3cc(O)cc(OC)c32)cc1O</smiles>

$\mathrm{HO}$<smiles>COC1=CC(=O)c2c(ccc3cc(O)c(OC)cc23)C1=O</smiles>

26<smiles>COc1cc(O)cc(CCc2ccc(OC)c(O)c2)c1</smiles>

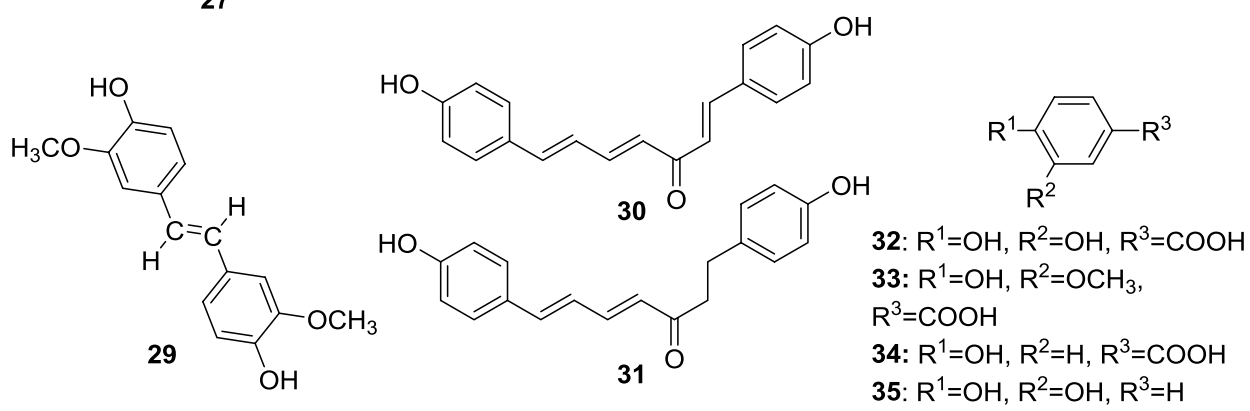<smiles>O=C1OC(c2ccccc2)Cc2cc(O)cc(O)c21</smiles>

36<smiles>[R]c1cc([R])c2c(=O)c([R])c(-c3ccc([R])c([R])c3)oc2c1</smiles>

37: $\mathrm{R}^{1}=\mathrm{OH}, \mathrm{R}^{2}=\mathrm{OH}, \mathrm{R}^{3}=\mathrm{OH}, \mathrm{R}^{4}=\mathrm{OH}, \mathrm{R}^{5}=\mathrm{H}$ 38: $\mathrm{R}^{1}=\mathrm{OH}, \mathrm{R}^{2}=\mathrm{OH}, \mathrm{R}^{3}=\mathrm{OGlc}, \mathrm{R}^{4}=\mathrm{OH}, \mathrm{R}^{5}=\mathrm{H}$ 39: $\mathrm{R}^{1}=\mathrm{OH}, \mathrm{R}^{2}=\mathrm{OH}, \mathrm{R}^{3}=\mathrm{OGIC} \stackrel{6-1}{-} \mathrm{Rha}, \mathrm{R}^{4}=\mathrm{OH}$, $\mathrm{R}^{5}=\mathrm{H}$

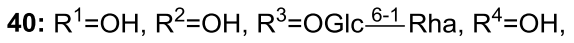
$\mathrm{R}^{5}=\mathrm{OH}$

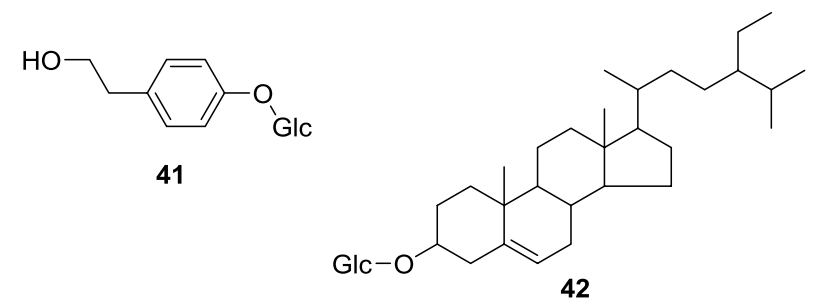<smiles>OC[C@@H](O)[C@@H](O)[C@H](O)[C@H](O)CO</smiles>

Fig. 5 Chemical composition of the aboveground parts of D. nipponica ( $\mathrm{GlC}=\beta$-D-glucopyranosyl, and Rha $=a$-L-rhamnopyranosyl) 
could be inhibited, while at a higher dose $(5 \mathrm{mg} / \mathrm{mL})$ it could be clearly inhibited rapidly $(30 \mathrm{~h})$. This implied that the inhibitory effect of RDN on cell proliferation was mainly in the excitation stage. The same research group [82] adopted the serum pharmacology method to study the impact of TSRDN on the ConA-induced splenic lymphocyte proliferation and the secretion of IL-2. The results of this study suggested that the drug serum of TSRDN can inhibit the IL-2 production and T-lymphocyte proliferation as well as the cellular immunity in mice.

$\mathrm{Yu}$ et al. $[75,76]$ studied the influence of TSRDN on the lipopolysaccharide (LPS)-induced splenic lymphocyte proliferation and the secretion of IL- 6 by using serum pharmacology in mice. A $20 \%$ concentration of TSRDN could prevent the LPS-induced splenic lymphocyte proliferation and IL- 6 generation, thus inhibiting the humoral immunity of mice.

Shu et al. [29] used the decoction of RDN to feed mice for 7 days, which caused the atrophy of thymus $(\mathrm{P}<0.01)$, the reduction of ANAE positive rate $(\mathrm{P}<0.05)$ and the inhibition of delayed-type hypersensitivity of skin $(\mathrm{P}<0.01)$. The formation of serum hemolysin was reduced $(\mathrm{P} \ll 0.01)$, but the impact on the spleen weight and structure was unclear $(\mathrm{P}>0.05)$. Further, the chicken erythrocyte cytophagy percentage in the mouse peritoneal macrophages and the phagocytic index as well as the serum lysozyme content were increased $(\mathrm{P}<0.01$ for all). This indicated that the cellular immunity and humoral immunity could be inhibited by RDN; whereas the phagocytosis of macrophages could be enhanced.

\section{Anti-tumor activity}

A number of reports have established the anti-tumor effects of RDN, dioscin and diosgenin on various tumor cells, and the anti-tumor mechanisms were discussed respectively [77].

Wang et al. [78] used four tumor cell strains (MCF, L929, A375-S2, HeLa) for the in vitro test and four mice portability tumors (S-180, HepA, U14, EAC) for the in vivo test of the anti-tumor effect of different concentrations of diosgenin. It was observed that diosgenin has a clear inhibitory effect on mice transplant tumors like S-180, HepA and U14 as well as the tumor cell strains like L929, HeLa and MCF.

Wang et al. [79] used the prosapogenin B (P.B) of dioscin on the human leukemia cell line $\mathrm{K} 562(10 \mu \mathrm{mol} / \mathrm{L})$ for $24 \mathrm{~h}$. The K562 cells displayed typical intranuclear chromatin condensation, nuclear segmentation, withering of cell volume, surface film bubbling of apoptotic cells, etc. The result showed that P.B could inhibit the proliferation of $\mathrm{K} 562$ cells by inducing apoptosis.

Hong et al. [80] tested the effect of diosgenin on the human osteosarcoma cell line (U-20S) and observed a strong inhibitory effect. In a subsequent research, they [81] used the tetrazole reduction method to observe the impact of diosgenin on the in vitro growth of tumor cells (U-20S, SGC-7901 and ACCM), as well as the normal cells (HUCB and hRPE). The results showed that diosgenin could inhibit the growth of both normal and tumor cells to different degrees; the dose for inhibiting normal cells was 2-11 times more than that for inhibiting tumor cells.

Several years later, the same research group [82] explored the mechanism of action of diosgenin on the in vitro growth of human osteosarcoma epithelial cells line (U-20S) via the tetrazole reduction method. The flow cytometry analysis revealed that diosgenin inhibited the $\mathrm{U}-20 \mathrm{~S}$ cell cycle in the $\mathrm{G}_{1}$ phase. The result showed that diosgenin had a clear inhibitory effect on the growth of U-20S cells, which has a certain value for the cure of osteosarcoma.

Hou et al. [83] studied the impact of dioscin on the cell cycle of breast cancer cells: dioscin downregulated the values in the phase $G_{0} / G_{1}$ and phase-S and upregulated the values of apoptotic cells in the phase $G_{2} / M$. This result indicated that breast cancer cell proliferation and their inhibition were related to the impact on the cell cycle and apoptosis induction. Later, Chen et al. [84] further explored the anti-tumor activity of dioscin through the portable mouse breast cancer animal model. It was observed that both the dosage and administration routes could affect the portable mouse breast cancer, and the effect of intraperitoneal injection was optimal. In later studies [85], the anti-tumor activity of dioscin on various solid tumor cells was studied by the in vitro cell culture technique, which provided the basis for further exploration of portable animal model studies, anti-tumor mechanism elucidation as well as new drug research and development.

Li et al. [86] studied the synergistic and toxicityreducing effect of diosgenin on the chemotherapy drug, 1-(2-tetrahydrofuryl)-5-fluorouracil (FT-207). The results showed that the combination of diosgenin with FT-207 could significantly enhance the anti-tumor activity on the mouse gastric adenocarcinoma cell line (MFC) and improve the immune function of macrophages while the toxic and side effects could be reduced as well.

Chen et al. [87] observed the impact of sapogenins on the tumor weight gain of poorly differentiated human gastric gland cancer cell strain (MGC-803) in nude mice. The result showed that diosgenin [400, 200 and $100 \mathrm{mg} /$ $\mathrm{kg}(\mathrm{ig})] \mathrm{had}$ an obvious dose-dependent inhibitory effect on the tumor growth with an average anti-tumor rate of $44.9-64.5 \%$.

In the papers of Li et al. [88] and Song et al. [89], the inhibitory effect of diosgenin on the cell division and 
colony formation of MGC-803 cell line was reported. The possible working mechanism was explored as well, i.e., diosgenin could directly inhibit the DNA synthesis of MGC-803 cells at low concentrations (3.750 and $7.500 \mathrm{mg} / \mathrm{L}$ ) with a median inhibitory concentration $\left(\mathrm{IC}_{50}\right)$ of $13.17 \mathrm{mg} / \mathrm{L}$.

\section{Effects on the respiratory tract}

Bronchial asthma is a chronic airway inflammation disease with the participation of various cells (eosinophils, mastocytes, T-lymphocytes, neutrophils, and airway epithelial cells) and cellular components. Its pathogenesis is complicated, including allergic inflammation, airway remodeling, airway hyperresponsiveness, etc.

Cai et al. [90] studied the effect of TSRDN on the Ovalbumin (OVA)-induced airway remodeling and $\alpha$-smooth muscle actin ( $\alpha$-SMA) of specific-pathogen-free (SPF) level $50 \mathrm{BALB} / \mathrm{c}$ asthmatic mice. The mice were randomly divided into the blank group, model group, highdose group, middle-dose group and the low-dose group of TSRDN. In the experiment (18-55 days), mice of the blank group and the model group were administered with normal saline gavage, while the drug groups were given 80,40 , and $20 \mathrm{mg} / \mathrm{kg}$ of TSRDN. At the end of the experiment, the lung tissue pathomorphism change was observed and the immunohistochemical method was adopted to test the $\alpha$-SMA level. The results showed that TSRDN could inhibit the lung tissue expression of $\alpha$-SMA in asthmatic mice, affect the skeletal muscle thickening, and improve the airway remodeling status.

Wang et al. [91] used the OVA-sensitization method to establish an asthma rat model along with grouping and drug administration for 7 days. The eosinophilic granulocyte (EOS) infiltration in bronchoalveolar lavage fluid (BALF) of rats and the lung tissue pathological changes like inflammation were observed. The results indicated that the EOS infiltration in the BALF and lung tissue, pathological changes of the lung tissue and the airway inflammation in the $D$. nipponica treatment groups was significantly lower than that in the model group.

Zhang et al. [92] adopted the traditional Chinese prescription for D. nipponica together with ligustrazine acupoint injection to manage and treat bronchial asthma. The results showed that the total effective rate of the treatment group was $92.42 \%$ and that the markedly effective rate was $56.06 \%$, which were superior to 83.33 and $26.67 \%$ of the control group $(\mathrm{P}<0.05)$. At the same time, the improvement of the pulmonary function, IgE and other detection indicators were clearly superior to those of the control group $(\mathrm{P}<0.01)$. It was proved that the drug can inhibit the platelet aggregation and release, and has the effects of reducing phlegm, clearing away lungheat and relieving asthma.
Into the ammonia-induced mouse coughing method, oral administration of total saponin, water-soluble or water-insoluble saponin, no. 1 molecular sieve and intraperitoneal injection of decoction can achieve a significant anti-tussive effect, but diosgenin and high-dose steroidal saponin were ineffective. Li et al. [31] have separated an acidoid from the water-soluble components, which has a strong anti-tussive effect. According to the mouse phenol red method, oral administration of total saponins, water-insoluble saponin, no. 1 molecular sieve or intraperitoneal injection of decoction can have a significant expectorant effect [31].

\section{Anti-inflammatory and analgesic activity}

Rheumatoid arthritis (RA) is a chronic auto-immune disease manifested as joint synovitis, synovial membrane pannus formation, and cartilage as well as bone tissue erosion. Angiogenesis and pannus formation play the central role in promoting RA, which is in turn affected by vascular endothelial growth factors (VEGF). Several studies indicated that TSRDN could inhibit the abnormal expression of synoviocyte VEGF in collagen-induced arthritis (CIA) mice and relieve the angiogenesis and inflammatory response [93].

Lv et al. [94] studied the effect of D. nipponica treatment on the urate crystal-induced acute gouty arthritis in rats. 56 rats were randomly divided into the control group, model group, colchicine group, $D$. nipponica group A (15 g/kg/day), D. nipponica group B (12 g/ $\mathrm{kg} /$ days $), D$. nipponica group C $(6 \mathrm{~g} / \mathrm{kg} /$ days $)$ and $D$. nipponica group D (3 g/ $\mathrm{kg} /$ day). Compared with the model group, the joint swelling in $D$. nipponica treatment groups at each time point had decreased to different extents. Therefore, moderate and high doses of $D$. nipponica have certain treatment effect on acute gouty arthritis, which may be realized through the inhibition of white blood cell generation and the secretion of the important inflammation transmitter IL-1 $\beta$.

Dong et al. [95] discussed the effect of TSRDN on the synovium angiogenesis and VEGF expression of CIA rats. The study found that the levels of rat synovium microvessel density (MVD) and VEGF of the model group were significantly lower than that in the treatment groups, suggesting that TSRDN can relieve the angiogenesis and inflammatory reaction via the inhibition of abnormal VEGF expression. A few years later, the same group [96] established a CIA rat model and observed the influence of TSRDN on inflammatory cytokines in the serum of type-II CIA rats, and the possible working mechanism of TSRDN in curing RA was discussed. The result showed that TSRDN could significantly decrease the levels of TNF- $\alpha$, IL- $1 \beta$, and IL- 6 in the serum of CIA rats, alleviate 
the pathological damage of synovial tissue and may play a role in the treatment of RA.

Tang [97] used xylene and carrageenan to induce inflammation and conducted the mouse writhing reaction test. It was observed that $D$. nipponica could significantly inhibit the xylene-induced ear inflammation and carrageenan-induced ankle swelling in rats, reduce the permeability of mouse abdominal cavity capillaries and inhibit the cotton ball granuloma in rats. Furthermore, it can prolong the pain reaction time and reduce the writhing time in mice. Thus, it was concluded that D. nipponica had obvious anti-inflammatory and analgesic effects.

Yao et al. [98] studied the effect of D. nipponica on microcrystalline sodium urate-induced acute gouty arthritis of rats and oteracil potassium-induced hyperuricemia model of mice. The screening of pharmacodynamic indices, such as anti-inflammatory, analgesic, uric acid decrease, etc. was performed. A 30\% alcohol elution of the $D$. nipponica water extract significantly reduced the blood uric acid level of mice with hyperuricemia, improved the pathomorphological change of the joint synovium tissue of rats, and decreased the writhing times; so, it was considered as an effective treatment for acute gouty arthritis.

Tong et al. [99] adopted the mouse peritoneal capillary exudation and cotton ball granuloma methods to compare the anti-inflammatory effects of the aboveground and the rhizome water extracts of $D$. nipponica (WERDN). The results showed that WERDN significantly reduced the exudation of peritoneal fluid and the weight of granuloma in mice, thus inhibiting the increase of early blood capillary exudation and the proliferation of late granulation tissue. The same research group [100] carried out a comparative research on the anti-inflammatory effect of aboveground and WERDN collected at the same time and in the same place by using the auricle swelling experiment, cotton ball granuloma and peritoneal fluid methods in mice. For the mouse cotton ball granuloma model, the intragastric administration of TSRDN for 7 days significantly alleviated the ear swelling, reduced the weight of granuloma, and decreased the peritoneal fluid in exudation. These results suggested that TSRDN had a clear anti-inflammatory activity.

Pang et al. [101] established a carrageen-induced acute non-infection inflammatory model of podedema of mice. 3 days before modeling, different doses of $D$. nipponica decoctum were used for gavage once per day. In the simulation, serum sialic acid levels and the thickness of foot pad was measured every $2 \mathrm{~h}$ before and after the modeling. It was concluded that $D$. nipponica could significantly alleviate the carrageen-induced swelling of the foot in mice, and it has no impact on the serum sialic acid levels. Du et al.
[102] used the rat CIA model to study the therapeutic effect $D$. nipponica. Intragastric administration of $D$. nipponica water decoction reduced the CIA ankle swelling rate and improved the ankle pathological state.

Xie et al. [103] adopted TSRDN gavage treatments in various doses to improve the joint inflammatory symptoms of rats with adjuvant arthritis. The treatment caused a reduction in joint swelling, inflammation index, inflammatory reaction morbidity, cartilage damage and the degree of severity.

\section{Other effects}

The pharmacological studies have confirmed that the $D$. nipponica extract or its components have effects of antiaging [104], blood fat-reducing [105, 106], thyroid-regulating and anti-platelet aggregation.

\section{The effect on the thyroid}

Wang et al. [107] used the D. nipponica extract on Graves' disease (toxic diffuse goiter) rat model and concluded its anti-thyroid activity. On the basis of this work, sodiumiodide symporter (NIS) mRNA expression was measured by similar means, and the result showed that $D$. nipponica could strongly inhibit the expression of NIS mRNA, thus inhibiting the effect of iodine capture [108]. After a 1-month gavage of $D$. nipponica, the electron microscopy technique was used to observe ultrapathological changes of rats' thyroid tissue which revealed an improvement in the hyper-pathological disorder of the thyroid tissue in Graves' disease [109].

\section{The effect on platelet aggregation}

Ning et al. [110] observed that diosgenin could inhibit the thrombosis of rats in vitro and vivo, could reduce the dry and wet weight of thrombus, prolong the thrombosis time in vivo, and reduce the whole blood viscosity as well as plasma viscosity. As a result, it provided an experimental basis for the clinical treatment of ischemic heart diseases and cerebrovascular diseases.

\section{Clinical applications}

The dry rhizome of $D$. nipponica has the effect of expelling wind-damp; relieving pains; relaxing muscles and stimulating blood circulation; helping digestion and promoting urination; relieving cough, asthma and eliminating phlegm. It can be used for the treatment of rheumatoid arthritis, lumbar and leg pains, traumatic injuries, chronic bronchitis, and tumors. At present, the clinical application of the rhizome of D. nipponica reported in the literature is mainly concentrated on the following aspects: 


\section{The treatment of arthritis}

\section{The treatment of rheumatoid arthritis}

45 cases (35 male and 10 female) with rheumatoid arthritis were treated with intramuscular injection of $D$. nipponica $(1 \mathrm{~g} / \mathrm{mL})$ twice a day. $84 \%$ of the patients' treatment process took a month and $16 \%$ of the patients' treatment took 2 months. The obvious effective, improvement and the total effective rates were 40,43 and $83 \%$, respectively. There were no significant adverse reactions, and the short-term effect was positive. 222 cases with rheumatic and rheumatoid arthritis were treated by administering D. nipponica (150 g) and dog bone (100 g) with the obvious effective, effective and total effective rates of $65.87,27$, and $92.7 \%$, respectively $[57,111]$. The prescription was composed of the D. nipponica, Caulis spatholobi and Zingiberis rhizome. It was used to treat rheumatic arthralgia and had the effects of dispelling wind and eliminating dampness, promoting blood circulation to remove the meridian obstruction, and eliminating cold to stop pain [112].

Dioscorea nipponica (10-15 mL) extract was administered orally thrice a day for 15 days and the symptoms could be relieved after only 7 days. 24 cases with brucellosis combined rheumatic arthritis were treated by using the D. nipponica injection (anti-“O” 1: over 400). The anti-"O" of 15 cases has decreased after treatment, of which 11 cases were negative. Thus, it was considered to be related to $D$. nipponica effect of inhibiting the streptococcus as well as the steroid hormones [113].

\section{The treatment of osteoarthritis}

Osteoarthritis is a common disease among the middleaged and old populace, leading to chronic cartilaginous damage. The intraosseous hemodynamic abnormality that is characterized by venous blood stasis and corresponding high intraosseous pressure may be one of the main causes for the occurrence of the disease. In a study, D. nipponica decoction was used to treat 35 cases with knee osteoarthritis at 1 dose/day during a course of 30 days, where the degree of arthralgia, joint pressing pain, the degree of joint swelling and joint function grading were regarded as the observation indices. The total effective rate of the treatment course was 94.3\% $(\mathrm{P}<0.05)$ which indicated that $D$. nipponica had a good curative effect on osteoarthritis of the knee joint [114].

Among 128 cases of patients with knee osteoarthritis orally taking traditional Chinese medicine along with the external application of the bone spur medicine containing D. nipponica, 61 cases had been cured (47.7\%), 38 cases had an obvious positive effect (29.7\%), 23 cases had a positive effect (18\%), and the total effective rate was 95.4\% [115].

\section{The treatment of acute suppurative arthritis}

Among eight cases of acute suppurative arthritis resistant to antibiotics, six were with pyemia (Staphylococcus aureus in blood culture). After treatment with $D$. nipponica decoction (adults: 150 g; children: 100 g) twice a day, five cases have been cured [116].

\section{The treatment of coronary heart disease and angina}

Coronary heart disease is one of the most common diseases that threaten health and life. Its major risk factors include high blood pressure, dyslipidemia, overweight/ obesity, hyperglycemia/diabetes, unhealthy lifestyles such as smoking, irrational diet (high fat, high cholesterol, high calorific value, etc.), lack of physical activity, excessive drinking, and social psychological factors. Therefore, lipid-lowering, anti-coagulation, blood viscosity improvement and coronary blood flow volume increase are the key criteria for the treatment.

Diao xin xue kang capsules made from the rhizome extracts of $D$. panthaica or $D$. nipponica can promote blood circulation and remove blood stasis, dilate coronary blood vessels, improve myocardial ischemia, etc. It can be used to prevent and cure coronary heart disease, angina, chest apoplexy, dizziness, and shortness of breath, palpitations, chest distress or pain caused by internal/external bleeding [117].

The Weiaoxin group (treatment) contains 33 cases (20 male and 13 female), and Diao xin xue kang group (control) has 32 cases ( 24 male and 8 female). For 4 weeks, the treatment group took Weiaoxin pills $(160 \mathrm{mg})$ and the control group took Diao xinxuekang capsules $(200 \mathrm{mg}$ ) orally, thrice a day. During the period of observation, low fat and low salt diet were applied for the cases with high blood pressure and other relevant drugs except the quick-acting nitroglycerin were stopped. Both Weiaoxin and Diao xin xue kang had a similar effect on alleviating angina and reducing nitroglycerin dosage, but the total effect on improving electrocardiography, coronary and myocardial blood flow by Weiaoxin was superior to that of Diao xinxuekang $(\mathrm{P}<0.05)$ [118].

Zhang et al. [119] used Weiaoxin pills to study the prevention and treatment of vasculopathy in diabetic patients. Weiaoxin pills (160 mg, 3 times a day) were used for 30 days in a row and then the dose was reduced (80 mg, 3 times/day). After administering for another 30 days, the thromboxane B2 (TXB2) in the serum, 6-ketone-prostaglandin F1 $\alpha$ (6-Keto-PGF1 $\alpha)$ content and hemorheology were tested. The results showed that Weiaoxin pills could reduce the whole blood viscosity, plasma viscosity and fibrinogen to different extents, decrease the blood concentration coefficient and the microcirculation detention times. So, its effect was significantly better than the conventional treatment group, 
indicating that oral administration of Weiaoxin pills in the early stages can effectively prevent diabetes and diseases of blood vessels.

Chuanlong guanxinning tablets are made from the rhizomes of $D$. nipponica, mainly composed of diosgenin. Through the clinical application for 302 cases of 18 clinical units in Sichuan Province, it was proved that Chuanlong guanxinning is effective for improving coronary blood supply, treating coronary heart disease, angina, palpitations, shortness of breath, choking, and high blood pressure [71].

In another clinical study, Chuanlong guanxinning was used for the treatment of 216 cases with coronary heart disease: 101 cases received one course and 115 cases received two treatment courses. The cases took $160 \mathrm{mg}$ each time, three times a day over a course of 3 months. Among the 216 cases, 101 cases suffered angina before the treatment. Among them, 53 cases achieved effective results after the treatment, 93 cases' symptoms were improved, and 14 cases had no effect. It was proved clinically that Chuanlong guanxinning had a significant effect in curing coronary heart disease and angina, with an effective rate of $91 \%$. It was relatively effective for palpitations, shortness of breath and chest choking, with an effective rate of $77.3 \%$. It can improve the insufficiency of coronary artery blood supply, hypertriglyceridemia and prevent the high blood pressure associated with coronary heart disease [120].

Wang [121] randomly selected 160 patients diagnosed with coronary heart disease and angina and evenly divided them into the treatment and control groups. The treatment group contained 42 males and 38 females with the average age of 59.3 years, among which 53 cases of unstable angina, 21 cases of stable angina, and 6 cases of old myocardial infarction were present. 80 cases with angina were cured with Weiaoxin with a total clinical effective rate of $90 \%$, and the total effective rate of the electrocardiogram improvement was 65\%. Moreover, adverse reactions such as bleeding, allergy and headache were not seen during the treatment.

\section{The treatment of chronic brucellosis}

Brucellosis, especially chronic brucellosis is a common and frequently-occurring disease that has a long-term effect on public health and life. 302 cases with chronic brucellosis (186 male and 116 female) were treated with two dosage forms i.e., D. nipponica injection and syrup, by Gao [122]. The supervised No. 1 pill of traditional Chinese medicine was applied for the control group. The two preparations of $D$. nipponica can play the role in alleviating the clinical symptoms of chronic brucellosis and eliminating joint and nerve pain. The cure rate of the injection group was $32.14 \%$ with a basic cure rate of $38.4 \%$; the cure rate of the syrup group was $24 \%$ with a basic cure rate of $2 \%$; and the cure rate of the control group was $12.3 \%$ with a basic cure rate of $24.61 \%$. The above data suggested that $D$. nipponica has clinical value for chronic brucellosis [122, 123].

Han [124] treated 231 cases of chronic brucellosis with an intramuscular injection of D. nipponica. The injection $(4 \mathrm{~mL})$ was applied once every other day or once a day, over a course of 10 days. The interval between the courses was 5-7 days, with 3 courses in total. The results showed an obvious curative effect on alleviating and eliminating arthralgia, headache, tiredness and pantalgia. Through the short-term and long-term clinical observations, the cure rate was $9.4 \%$, the effective rate was $83.5 \%$ and the recurrence rate was $83.5 \%$.

\section{The treatment of chronic bronchial asthma}

Zhang et al. [92] used D. nipponica decoction and ligustrazine point injection simultaneously in 66 cases with bronchial asthma where the total effective rate was $92.42 \%$, and the obvious effective rate was $56.06 \%$. The control group contains 30 cases that were treated simultaneously with Ma xing Shi gan tang decoction and aminophylline point injection. The composition of the prescription includes D. nipponica, ephedra, Chinese thorowax root, Fangfeng, Schisandra chinensis, Angelica sinensis, Astragali radix, Fructus psoraleae, Rehmannia root, Scutellaria baicalensis, Rheum officinale, and liquorice. The prescription could help to clear heat and eliminate phlegm, relieve asthma, nourish the kidney and sooth the liver, activate blood and relieve rheumatic pains. It was also verified by the modern pharmacology of traditional Chinese medicine that the above drugs could inhibit the adhesion and chemotaxis of the airway inflammatory cells, reduce inflammatory mediators and IgG content, and improve the inhibitive T-lymph cell functions.

By treating 37 cases of chronic bronchitis with the decoction of $D$. nipponica pills, the total effective rate was $86 \%$, while for 142 cases it was $94 \%$. The effective rates of the simple and resistance types were higher, i.e., $86 \%$ and $82 \%$, respectively. The relief effect of cough, asthma and phlegm was favorable. The effect on the resistance type with repeated infection was very poor, and the effect of using D. nipponica alone for those with acute occurrence and respiratory tract infection caused by cold was unclear. After taking the Scutellaria baicalensis decoction simultaneously, the effect was significantly positive [4].

32 cases with serious bronchial asthma were treated by Lei [125] through the conventional treatment using western medicines. The clinical effect of serious bronchial asthma through Fei shu point injection of D. nipponica 
along with conventional treatment of Western medicines was observed for 2 weeks. The results showed that the total effective rate was $78.13 \%$ and there were different degrees of improvement for the lung function indices of patients. Thus, the point injection of D. nipponica was relatively effective and safe for the treatment of serious bronchial asthma.

\section{The treatment of lipoma}

Dioscorea nipponica $(250 \mathrm{~g})$ was soaked at $60{ }^{\circ} \mathrm{C}$ in wine $(2000 \mathrm{~mL})$ for half a month and administered to a patient with scapulohumeral periarthritis. Though the result was not clear for scapulohumeral periarthritis, the twodecade old egg-sized lipoma on the hip of the patient had become soft and small unexpectedly. After oral administration for 3 months, the lipoma had completely disappeared. Therefore, the combination of $D$. nipponica and wine was considered to be optimal as the former has the effect of activating blood and the latter has the function of dredging collaterals [126].

\section{Toxic and side effects}

Adverse reactions of $D$. nipponica include diarrhoea, astriction, abdominal discomfort accompanied by nausea, emesis, stomatitis, epistaxis, dizziness, increased menstrual volume, swelling at the injection site, blurred vision and temporary increase of glutamate pyruvate transaminase (GPT). These symptoms would disappear once the drug use is suspended and during the treatment, all these symptoms should be noted [5].

The toxicity of the water-soluble TSRDN varies through administration routes. In mice, the maximum tolerated dose (MTD) through oral route was $15.6 \mathrm{~g} / \mathrm{kg}$ and the median lethal dose $\left(\mathrm{LD}_{50}\right)$ was $2.21 \pm 0.14 \mathrm{~g} / \mathrm{kg}$. The $\mathrm{LD}_{50}$ of TSRDN intravenous injection was $750 \mathrm{mg} / \mathrm{kg}$ while that of its pure product was $406-425 \mathrm{mg} / \mathrm{kg}$. $60-180 \mathrm{mg} /$ $\mathrm{kg}$ daily gavage for mice was conducted for 7 weeks consecutively, and the result showed no clear influence on the hemogram, liver and spleen function. Through visual observation of the heart, liver, spleen, lung, kidney, adrenal gland and other key organs, no pathologic change had been found. According to Wang Miaofang et al. [127], the main constituent of the Wei Ao Xin medicine was watersoluble total saponin which could cause an increase in the release of bradykinin and prostaglandins E2 that leads to dry cough, due to the stimulation of the respiratory tract.

Liang et al. [128] used the gavage and hypodermic injection to observe the acute toxic effect of TSRDN in mice. The MTD of the TSRDN gavage for 7 days consecutively after one-time drug administration was $0.42 \mathrm{~g} /$ $\mathrm{kg} / \mathrm{d}$. The $\mathrm{LD}_{50}$ of TSRDN caused by the gavage was not measured by the result but equivalent to 1355 times the MTD of the daily clinical dose of adults. The $\mathrm{LD}_{50}$ of hypodermic TSRDN injection of mice was $0.17 \mathrm{~g} / \mathrm{kg}$, indicating that the oral drug administration of TSRDN was relatively safe. In addition, TSRDN may have a certain influence on the gastrointestinal tract of mice, which needs further long-term toxicity observations.

Zhou et al. [129] used the in vitro 3-(4,5-dimethythiazol-2-yl)-2,5-diphenyl tetrazolium bromide (MTT) method to detect the alanine aminotransferase (ALT), alkaline phosphatase (ALP) and lactate dehydrogenase (LDH) content in the liver due to dioscin toxicity. According to experimental research on mice, after 7 days of dioscin administration $(10 \mathrm{mg} / \mathrm{kg})$, the aspartate aminotransferase (AST) and LDH levels in Kunming mouse serum have increased. The liver of one mouse showed wide edema of hepatocytes, and two mice showed occasional meganucleus hepatocyte, implying that large doses of dioscin might be harmful to the liver to some extent. So, the clinical use of drugs with dioscin should be cautious, especially for patients with poor liver function.

\section{Discussion}

The significance of $D$. nipponica in Traditional Chinese Medicine has led to the isolation of numerous steroid saponins during the last few years possessing furostane-, spirostane-, and pregnane-type aglycones. The isolation was done following standard procedures, while the structure elucidation was performed with the help of advanced spectroscopic (NMR, MS, etc.) techniques. Numerous in vitro and in vivo assays helped researchers to characterize several pharmacologically active steroid saponins in D. nipponica possessing anti-tumor, immunoregulatory, analgesic, anti-microbial, anti-platelet, anti-ischemic, anti-anginal, anti-asthmatic, anti-inflammatory, and anti-allergic activities. These comprehensive pharmacological investigations have revealed that the therapeutic applications of D. nipponica are substantial and invaluable.

However, the clinical trials are still very few and more evidence-based clinical trials are required to study the efficacy of $D$. nipponica. Its toxic effects on liver should be taken into consideration before calculating the dose and preparing the dosage regimens in clinical therapeutic applications. Hence, the mechanisms involved in the toxic and side effects, as well as the safety profile of the $D$. nipponica extracts, need to be studied well and the toxic metabolites need to be characterized. In addition, synergism and reduced toxic effects has been achieved through the combination of D. nipponica with other herbal medicines. Further, the major drawbacks of potent chemotherapeutic drugs are toxicity to normal tissues and drug resistance. In this context, dietary supplementation, as well as phytotherapeutic agents with high anti-cancer 
activity and less toxicity, has been considered as potential candidates for their capacity to enhance the efficacy of anti-cancer drugs.

Dioscorea nipponica has high medicinal value, extensive utility and encouraging market prospects. Various synthetic contraceptives and most steroid hormone drugs in the world are made from dioscin. Annually, there is a worldwide requirement for 8000 tons of dioscin, but actually, only 3000 tons can be produced [130]. With unique medicinal values, $D$. nipponica has become a rare resource snapped up by biopharmaceutical enterprises. As wild resources are nearly exhausted, steroid medicinal resource plants are in short supply, while the artificial cultivation of $D$. opposita is in face of degenerated quality and low output, making the raw material of $D$. nipponica extremely insufficient $[131,132]$.

\section{Measures proposed to deal with the exhaustion of $D$. nipponica resources Strengthening the protection of wild $D$. nipponica}

The development and utilization of $D$. nipponica resources are relatively slow, but its application scope and demand have been increasing with people's deepening understanding. The gradual reduction, as well as free utilization of wild resources, has resulted in the failure of meeting the market demand. In addition, D. nipponica grows mainly on the hillsides, which allows it to be exploited easily by humans.

\section{Strengthening the study on D. nipponica cultivation techniques}

The industrial cultivation of D. nipponica has a short history; so, many problems need to be resolved urgently. In recent years, numerous studies on the cultivation techniques of $D$. nipponica have been conducted. The original dimming production skills have been changed, which has led to the significant reduction of production costs and dramatic increase in output. According to the biological characteristics of $D$. nipponica, the age of harvesting and production should be prolonged appropriately to get high outputs. Since the percentage of active constituents varies with different cultivation techniques and geography; the cultivation should be standardized to yield chemically standard herb. Secondly, there is a need for the development of the plant strains which are resistant to various plant diseases.

\section{Establishing normalized and intensified planting bases of $D$. nipponica}

The steroid content of $D$. nipponica is taken as the index, which verified that cultivated $D$. nipponica has relatively higher quality than wild ones. The main reason is that the synthesis of steroid saponins is closely related to the illumination. As a herbaceous twiner, D. nipponica needs to climb on other plants in natural habitat, so it has weak illumination. The cultivated D. nipponica receives full illumination which is beneficial to the synthesis of dioscin, thereby providing a favorable technical support for the culture prospects. In cultivated plants, the content of diosgenin can be much higher than wild products. Through various breeding and culture techniques, the content of diosgenin could be improved continuously. As a cash crop for farming industry adjustment in rural areas, the development of $D$. nipponica has huge potential. New culture techniques of $D$. nipponica, and comprehensive technical developments like saponin extraction and in-depth processing, have provided a more extensive development prospect, which is conductive to the economic and social benefits.

\section{Problems associated with the extraction of bioactive compounds}

The following are some of the problems faced during the extraction of bioactive compounds from D. nipponica: The rate of extraction and separation are generally low, and only the extraction of diosgenin is given priority, while other bioactive compounds such as the starch and tannin are neglected, which results in the waste of valuable resources [132]. The organic solvent extraction method is generally used, but the organic solvents are toxic and pollutants to the environment. Hence, the following aspects should be noted in future research and development: The extraction technique can be optimized along with rational utilization of the bioactive compounds; the cost of critical fluid extraction can be reduced by improving the extraction techniques. Thus, these measures could effectively resolve the main problems like low extraction rate and environmental pollution.

\section{Conclusion and future perspectives}

This review has summarized the botanical, phytochemical and pharmacological properties, as well as the clinical applications of the traditional Chinese medicinal plant $D$. nipponica. The steroid saponins occurring in the plant have the effect of improving cardiovascular system, regulating immune function, reducing swelling, relieving phlegm, cough, and asthma, as well as preventing inflammation and pain. However, there is still no clear classification and in-depth studies on the chemical components of D. nipponica and their activities, so the pharmacological mechanism has not been understood well. Research on the pharmacological activities is still in the animal experiment phase with a few reports on the clinical applications; therefore, further studies are needed [73]. 
Due to the shortage of wild D. nipponica resources, the biological features, cultivation, development and utilization should be strengthened. By increasing the production and decreasing production costs, the development of the agriculture should be intensified. The comprehensive utilization of all the plant products will help to promote the cultivation as well as the protection of wild resources. With high economic value, $D$. nipponica is an abundant resource of bioactive compounds in China. As people are attaching greater importance to the human health, the research on $D$. nipponica, mainly its water-soluble active ingredients should be strengthened. Further research is necessary to determine the chemical structure of the compounds, which may be specifically applied to pharmacology and clinical applications. If effective drugs can be made using advanced synthetic techniques, they will play a key role in enhancing health. Therefore, this review would be valuable for promoting the development of $D$. nipponica as a safe modern pharmaceutical as well as for improving its clinical uses.

\begin{abstract}
Abbreviations
2,4-DNFB: dinitrofluorobenzene; 6-Keto-PGF1 a: 6-ketone-prostaglandin F1a ALP: alkaline phosphatase; ALT: alanine aminotransferase; ANAE: nonspecific acid esterase; AST: aspartate aminotransferase; BALF: bronchoalveolar lavage fluid; CIA: collagen-induced arthritis; CK: creatine kinase; ConA: concanavalin A; ELISA: enzyme-linked immunosorbent assay; EOS: eosinophilic granulocyte; FCM: flow cytometry; FT-207: 1-(2-tetrahydrofuryl)-5-fluorouracil; Glc: $\beta$-D-glucopyranosyl; GPT: glutamate pyruvate transaminase; HPLC: high performance liquid chromatography; I/R: ischemia-reperfusion; LDH: lactate dehydrogenase; LDH: lactate dehydrogenase; LPS: lipopolysaccharide; MDA: malondialdehyde; MTD: maximum tolerated dose; MTT: 3-(4,5-dimethythiazol2-yl)-2,5-diphenyl tetrazolium bromide; MVD: microvessel density; NIS: sodium-iodide symporter; NO: nitric oxide; OVA: ovalbumin; P.B: prosapogenin B; PAF: platelet-activating factor; RA: rheumatoid arthritis; RDN: Rhizoma Dioscorea nipponica; Rha: $a$-L-rhamnopyranosyl; RP-HPLC: reversed-phase HPLC; SOD: superoxide dismutase; SPF: specific-pathogen-free; SRBC: sheep red blood cell; TLC: thin layer chromatography; TSRDN: total saponins of Rhizoma Dioscreae nipponica; TXB2: thromboxane B2; VEGF: vascular endothelial growth factors; WERDN: rhizome water extracts of $D$. nipponica; $a-S M A$ : a-smooth muscle actin.
\end{abstract}

\section{Authors' contributions}

TY and LZ initiated and designed the review. SHOY and TJ collected the literatures and drafted the manuscript. All authors contributed to literatures analysis and manuscript finalization. All authors read and approved the final manuscript.

\section{Author details}

1 School of Chinese Medicine, Hong Kong Baptist University, Kowloon Tong, Hong Kong Special Administrative Region, China. ${ }^{2}$ College of Chemistry, Leshan Normal College, Leshan 614004, China.

\section{Acknowledgements}

This work was the Guangdong Natural Science Foundation (2016A030313008) and the Shenzhen Science and Technology Innovation Committee (JCYJ20160518094706544).

\section{Competing interests}

The authors declare that they have no competing interests.

\section{Availability of data and materials}

All data are fully available without restriction.
Consent for publication

All authors agree to publish this article.

Ethics approval and consent to participate

Not applicable.

Funding

This work was the Guangdong Natural Science Foundation (2016A030313008) and the Shenzhen Science and Technology Innovation Committee (JCYJ20160518094706544).

\section{Publisher's Note}

Springer Nature remains neutral with regard to jurisdictional claims in published maps and institutional affiliations.

Received: 7 April 2018 Accepted: 28 April 2018

Published online: 11 May 2018

\section{References}

1. The State Pharmacopoeia Commission of P. R. China (2010) Pharmacopoeia of the People's Republic of China, vol 1. Chemical Industry Press, Beijing, p 250

2. Tang YN, Zhang H, Li J et al (2008) Pharmacognostic identification of original plants of rhizoma Dioscoreae nipponica and rhizoma Dioscoreae panthaicae. West China J Pharm Sci 23(4):444-447

3. Feng JF, Tang YN, Ji H et al (2017) Biotransformation of Dioscorea nipponica by rat intestinal microflora and cardioprotective effects of diosgenin. Oxidative Med Cell Longev 2017:4176518

4. Tang YN, He XC, Chen QL et al (2014) A mixed microscopic method for differentiating seven species of "Bixie"-related Chinese Materia Medica. Microsc Res Tech 77:57-70

5. Wang BX (2004) Modern pharmacology and clinic of chinese traditional medicine. Tianjin Science \& Technology Translation \& Publishing CO. LTD, Tianjing, pp 1149-1150

6. Zhou QL, Wang T, Wang BX (2012) Modern principles and clinic on Chinese materia medica. Tianjin Science \& Technology Translation \& Publishing CO. LTD, Tianjing, pp 956-958

7. Tao YY, Zhang B, Yu HS et al (2007) Production and properties of saikosaponin-glycosidase. J Dalian Inst Light Ind 26(2):120-123

8. Zhang SX, Zhou LY, Yu YJ (2005) Study progress of Dioscorea nipponica Makino. Mol Plant Breed 3(1):107-111

9. Tang YN, Yi T, Chen HM et al (2013) Quantitative comparison of multiple components in Dioscorea nipponica and D. panthaica by ultra performance liquid chromatography coupled with quadrupole time-of-flight mass spectrometry. Phytochem Anal 24:413-422

10. Zhang N, Kang TG, Yin HB (2010) Advances of the study on chemical constituents and pharmacological activities of Dioscorea nipponica Makino. Res Pract Chin Med 24(6):87-90

11. Nanjing University of Chinese Medicine (2006) The dictionary of chinese medicinal herb. Shanghai Science and Technology Press, Shanghai

12. Institute of Botany (2002) The Chinese academy of science. High Plants China. 13:344-345

13. Zhao RN (2004) Chinese herbal medicine resources in Gansu Province. Gansu Science and Technology Press, Gansu

14. Mi YN (1989) The botanical drug of Nei Mongol. Nei Mongol People Publishing Press, Nei Mongol

15. Ding Y (2001) Chinese yam and Dioscorea nipponica. China Press of Traditional Medicine, Beijing

16. Sun QS (2004) Pharmaceutical botany. China Medical Science Press, Beijing

17. Liu SE (1959) Medica flora of Northeas. Science and Technology Press, Hunan

18. Hubei Health Bureau (1982) Chinese materia medica of Hubei. Hubei People Publishing Press, Hubei

19. Zhao YC, Jiang JY (1995) Chinese materia medica of Zibo. China Press of Traditional Medicine, Beijing 
20. Editorial Board of The Botanical Drug of Hunan (2004) The botanical drug of Hunan. Hunan Science and Technology Press, Hunan

21. Editorial Board of The National Assembly of Chinese Herbal Medicine (1983) The national assembly of Chinese herbal medicine. People's Medical Publishing House, Raleigh

22. Pei MY (2006) The cultivation technology of Dioscorea nipponica. Ginseng Res 18(3):41

23. Zhang JF, Pang ZY, Huang CH (2003) Resources developments and cultivation techniques of Dioscorea nipponica. Ginseng Res 15(3):30-31

24. Feng GH (2010) The semi-manual cultivation of Dioscorea nipponica Makino. Nongcun Shiyong Keji Xinxi 5:9-10

25. Du SH, Liu WY, Fu TJ et al (2002) Isolation and identification of steroida sapogenins from total sapogenin of Dioscorea nipponica Makino. J Chin Pharm Sci 3:59-63

26. Li R, Huang SX, Ding LS et al (2004) HPLC-MS analysis of chemical constituents from Dioscorea nipponica Makino. J Instrum Anal 23(z1):89-92

27. Kang LP, Ma BP (2005) Study on separation and identification of steroidal saponins of Dioscorea nipponica Makino. Chin Pharm J 40(20):1539-1541

28. Zhang JY (2007) Studies on the water soluble constituents of Dioscorea nipponica Makino. Shenyang Pharmaceutical University, Shenyang

29. Shu Y (2006) Studies of anticancer principles of Dioscorea nipponica Makino. Shenyang Pharmaceutical University, Shenyang

30. Wang ZJ, Luo DH (2007) Extraction, purification and antioxidant activities of polysaccharide from Dioscorea nipponica Makino. Nat Prod Res Dev 19:29-34

31. Li YM, He BJ, Liu ZY (1980) Research on the aqueous soluble active constituents of Dioscorea nipponica Makino. Acta Pharm Sinica 15(12):764-765

32. Zhang YQ, Cheng BS, Shao YF (1988) The amino acid analysis of 5 kinds of decoction pieces of traditional Chinese drug. Shandong Med Ind 7(4):48

33. Yi T, Fan LL, Chen HL et al (2014) Comparative analysis of diosgenin in Dioscorea species and related medicinal plants by UPLC-DAD-MS. BMC Boichem 15:19

34. Qin LY, Jia LY, Sun QS et al (2007) Determination of contents of dioscin and gracillin in Dioscorea nipponica Makino by RP-HPLC. J Shenyang Pharm Univ 24(10):627-630

35. Liu CZ, Zhou HY, Yan Q et al (2007) Fingerprint analysis of Dioscorea nipponica Makino by high-performance liquid chromatography with evaporative light scattering detection. Anal Chim Acta 582:61-68

36. Liu TQ, Yu HS, Liu CY et al (2013) Preparation of progenin III from total steroidal saponins of Dioscorea nipponica Makino using a crude enzyme from Aspergillus oryzae strain. J Ind Microbiol Biotechnol 40:427-436

37. Yin LH, Xu YW, Qi Y et al (2010) A green and efficient protocol for industrial-scale preparation of dioscin from Dioscorea nipponica Makino by two-step macroporous resin column chromatography. Chem Eng J 165:281-289

38. Tewtrakul S, Itharat A (2006) Anti-allergic substances from the rhizomes of Dioscorea membranace. Bioorg Med Chem 14:8707-8711

39. Lin SH, Wang DM, Yang DP et al (2007) Characterization of steroidal saponins in crude extract from Dioscorea nipponica Makino by liquid chromatography tandem multi-stage mass spectrometry. Anal Chim Acta 599:98-106

40. Tang YN, He XC, Ye M et al (2015) Cardioprotective effect of total saponins from three medicinal species of Dioscorea against isoprenalineinduced myocardial ischemia. J Ethnopharmacol 175:451-455

41. Gong GH, Qin Y, Huang W (2011) Anti-thrombosis effect of diosgenin extract from Dioscorea zingiberensis C. H. Wright in vitro and in vivo. Phytomedicine 18:458-463

42. Li H, Huang W, Wen YQ et al (2010) Anti-thrombotic activity and chemical characterization of steroidal saponins from Dioscorea zingiberensis C. H. Wright. Fitoterapia 81:1147-1156

43. Zhu JB, Guo XJ, Fu SP et al (2010) Characterization of steroidal saponins in crude extracts from Dioscorea zingiberensis C. H. Wright by ultraperformance liquid chromatography/electrospray ionization quadrupole time-of-flight tandem mass spectrometry. J Pharm Biomed Anal 53:462-474

44. Huang HZ, Zhao M, Lu L et al (2013) Pathways of biotransformation of zingiberen newsaponin from Dioscorea zingiberensis $\mathrm{C}$. H. Wright to diosgenin. J Mol Catal B Enzym 98:1-7
45. Zhou JJ, Xie GR, Yan XJ (2009) Traditional Chinese medicines molecular structures. Science Press, Beijing

46. Tang YN, Pang YX, He XC et al (2015) UPLC-QTOF-MS identification of metabolites in rat biosamples after oral administration of Dioscorea saponins: a comparative study. J Ethnopharmacol 165:127-140

47. State Administration of Traditional Chinese Medicine (2000) Chinese materia medica. Shanghai Science and Technology Prss, Shanghai

48. Feng B, Kang LP, Ma BP et al (2007) The substrate specificity of a glucoamylase with steroidal saponin-rhamnosidase activity from Curvularia lunata. Tetrahedron 63:6796-6812

49. Liu L, Dong YS, Xiu ZL (2010) Three-liquid-phase extraction of diosgenin and steroidal saponins from fermentation of Dioscorea zingibernsis $\mathrm{C}$. H. Wright. Process Biochem 45:752-756

50. Wanga T, Choi RC, Li J et al (2012) A steroidal saponin isolated from the Rhizomes of Dioscorea nipponica Makino, exerts protective effects against hyperlipidemia and oxidative stress. J Ethnopharmacol 139:214-220

51. Zhao XL, Jing WG, Han SY et al (2011) Two new steroidal saponins from Dioscorea panthaica. Phytochem Lett 4:267-270

52. Feng B, Ma BP, Kang LP et al (2005) The microbiological transformation of steroidal saponins by Curvularia lunata. Tetrahedron 61:11758-11763

53. Peng YE, Yang ZH, Wang YX et al (2011) Pathways for the steroidal saponins conversion to diosgenin during acid hydrolysis of Dioscorea zingiberensis C. H. Wright. Chem Eng Res Des 89:2620-2625

54. Du SH, Xia CD, Fu TJ (2000) Optimization in hydrolysis conditions of Dioscorea nipponica saponins. Chin Tradit Pat Med 22(9):608-610

55. He BJ, Liu ZY, Jin GS (1980) The separation and identification of benzyl tartaric acid of Yam water-soluble active ingredients of serotonin. Pharm Bull 15(10):39

56. Cui CB, Xu C, Gu QQ et al (2014) A new furostanol saponin from the water-extract of Dioscorea nipponica Mak., the raw material of the traditional Chinese Herbal Medicine Wei Ao Xin. Chin Chem Lett 15:1191-1194

57. Lu D (2008) The research about ground part of D. nipponica chemical composition and biological activity. Doctoral Dissertation of Jilin University, Jilin

58. Lu D, Wang CY, Liu JP (2007) Chemical constituents from aerial parts of Dioscorea nipponica. Chin Tradit Herb Drugs 38(12):1785-1787

59. Woo KW, Moon E, Kwon OW et al (2013) Anti-neuroinflammatory diarylheptanoids from the rhizomes of Dioscorea nipponica. Bioorag Med Chem Lett 23:3806-3809

60. Lu D, Liu JP, Li HJ (2010) Phenanthrene derivatives from the stems and leaves of Dioscorea nipponica Makino. J Asian Nat Prod Res 12:1-6

61. Lu D, Liu JP, Zhao YZ (2010) Chemical constituents from aerial parts of Dioscorea nipponica. Chin Tradit Herb Drugs 41 (5):700-703

62. Du HW (2010) Research and development of Dioscorea nipponica Makino and Dioscorea zingiberensis. Acta Chin Med Pharmacol 38(3):131-134

63. Zhang WF, Liu BS (2010) Research progress of pharmacological effects of dioscin. World J Integr Tradit West Med 5(6):543-545

64. Ni L, Xu P, Wu XS (2007) Antioxidative effect of dioscin on cardiomyocyte following hypoxia/reoxygenation injury. Shanghai J Tradit Chin Med 41(11):76-77

65. Gao WZ, Wang W, Fan XJ (2008) The protective effect of dioscin on cultured cardiomyocytesin anoxia/reoxygenation injury. Mol Cardiol China 8(2):72-74

66. Fan XJ, Jiao JJ, Zhao YQ (2008) Effects of dioscin on adenosine phosphates in rat myocardium with ischemia-reperfusion. J Tianjin Med Univ 14(4):409-411

67. Wei X, Shen BL, Zhang Z (2009) Effect of dioscin on the platelet activation in rats with myocardial ischemia-reperfusion injury. J Tianjin Med Univ 15(1):7-9

68. Ning KY, Li YK, Gao HL (2007) Effect of MPD on acute myocardial ischemia in dogs. Tradit Chin Drug Res Clin Pharmacol 18(6):417-421

69. Ning KY, Gao HL, Li YK (2007) Effects of MPD on heart hemodynamics in normal anesthetic dogs. Tradit Chin Drug Res Clin Pharmacol 18(6):421-424

70. Ning KY, Li YK, Gao HL (2008) Therapeutic effects of methyl protodioscin for myocardial infarction in rats. Tradit Chin Drug Res Clin Pharmacol 19(1):1-3 
71. Zhang KY, Chang TH, Li BJ (1982) The effect of Chuanlong guanxinning and water soluble saponins on rats myocardial nutritional blood flow volume. J China Med Univ 11(3):10-11

72. Gao W, Zhao TH, Song HR (2001) The effect of whole saponin of rhizoma Dioscorea Nipponicae to the immunity function in mouse. J Chengde Med Coll 18(1):9-10

73. Nan JY, Wang Z, Yang ZJ (1988) The effect of rhizoma Dioscorea Nipponicae to the immunity function. Chin Tradit Herb Drugs 19(3):22

74. Song HR, Gao JH, Fang YH (1998) The inhibition of T cell proliferation by Yam in vitro drug delivery. Journal of Chengde Medicine College 15(3):178-179

75. Yu HR, Wang JX, Chen JS (2007) Experimental study of the effect of Yam total saponins medicated serum on mice spleen lymphocyte proliferation and IL-6. Jiangsu J Tradit Chin Med 39(1):57-58

76. Yu HR, Wang JX, Song HR (2006) The pharmacological study of whole saponin of rhizoma Dioscoreae Nipponicae effect on rats'T Lymph cel function. Lishizhen Med Mater Med Res 17(9):1653-1654

77. Chien MH, Ying TH, Hsieh YS et al (2012) Dioscorea nipponica Makino inhibits migration and invasion of human oral cancer HSC-3 cells by transcriptional inhibition of matrix metalloproteinase-2 through modulation of CREB and AP-1 activity. Food Chem Toxicol 50:558-566

78. Wang $L$, Wang $Y$, Chen SW (2002) The antitumor activity of diosgenin in vivo and in vitro. China J Chin Mater Med 27(10):777-779

79. Wang SL, Cai B, Cui CB (2003) Apoptosis of human chronic myeloid leukemia K562 cell induced by prosapogenin B of dioscin (P.B) in vitro. Chin J Cancer 22(8):795-800

80. Hong ZQ, Lin JH (2001) The growth inhibition of Yam saponins ligands on bone sarcoma with U-20S cell. Fujian Med J 26(2):103-104

81. Hong ZQ, Lin JH (2005) The antitumor activity of diosgenin in vitro. J Fujian Coll Tradit Chin Med 15(4):35-37

82. Hong ZQ, Wang HM, Su YX (2009) Effect of diosgenin on proliferation and cycle of human osteosarcoma U-20S cell line. J Fujian Coll Tradit Chin Med 19(3):35-36

83. Hou L, Gao ZJ (2005) Effect of Yam saponin on cell cycle of mammary cancer. Chin J Basic Med Tradit Chin Med 11(11):831-832

84. Chen XY, Gao ZJ (2005) Study on the anti-cancer effect of dioscin on portability mouse breast cancer. Chin J Basic Med Tradit Chin Med 12(5):23-24

85. Gao ZJ, Chen XY (2005) Study on the anti-cancer inhibition effect of dioscin on portability mouse breast cancer in vitro. Chin J Basic Med Tradit Chin Med 12(7):33-34

86. Li HY, Li GZ, Yin JF (2007) Attenuation of diosgenin on FT-207 in tumorbearing mice. Chin Tradit Pat Med 29(5):655-658

87. Chen SW, Wang Y, Sun CJ (2003) Effect of diosgenin on tumor growth of nude mice bearing human gastric cancer (MGC-803). J Jilin Univ 29(2):145-146

88. Li JH, Li CA (2004) Inhibitory effect of diosgenin on human poorly differentiated gastric adenocarcinoma cell line. J Jilin Univ Med Ed 30(2):198-200

89. Song Y, He ZM, Li JH (2005) Effect of diosgenin on poor differentiated adenocarcinoma cells of human stomach. J Beijing Univ Tradit Chin Med 28(4):42-44

90. Cai XL, Wang Z, Jiang LB (2013) Effects of con-saponin of Dioscoreae Nipponicae on airway remodeling in asthmatic mice. J Zhejiang Univ Tradit Chin Med 37(6):756-760

91. Wang $Y$, Chen $X Q$, Wang $F$ (2013) The influence of Yam on airway inflammation of asthma rats. Chin J Tradit Med Sci Technol. 20(3):250-251

92. Zhang YP, Wang W, Wang SC (1998) The clinical observation about compound yam soup with point injection ligustrazine on treatment of bronchial asthma. J Emerg Tradit Chin Med 7(2):59

93. Guo YC, Dong WJ, Song HR (2013) Effects of dioscornin tablets on VEGF in synovial tissue of CIA rats. Mod Prev Med 4:712-714

94. Lv J, Miao ZM, Yan SL (2009) The effect of Dioscorea nipponica Makino on rats with acute gouty arthritis. Acta Acad Med Qingdao Univ 45(4):389-394

95. Dong W, Liang X, Qu Z (2010) Effects of total saponin of Rhizoma Dioscorea Nipponicae on angiogenesis in synovial membrane of CIA rats. J Chengde Med Coll. 27(4):360-362

96. Liang XJ, Sun TY, Dong WJ (2013) Effects of total saponin from rhizoma Dioscorea nipponica on inflammatory cytokines in collagen-induced arthritis rats. Lishizhen Med Mater Med Res 24(3):522-524
97. Tang LX (2000) The experimental research of the analgesic effect of Fujian yam anti-inflammatory. Strait Pharm J 12(3):38-40

98. Yao L, Liu SM (2010) Research of Dioscorea nipponica Makino on rats with acute gouty arthritis. Chin Arch Tradit Chin Med 28(8):1724-1726

99. Tong JM, Liu YL, Chen GH (2008) Study on anti-Inflammatory effect of water extract of aerial parts of Dioscorea nipponica Makino. J Chengde Med Coll 25(4):349-351

100. Tong JM, Yang YH, Shi YH (2009) Comparative study on anti-inflammatory effect of total saponins of aerial parts and the radicular of Dioscorea nipponica Makino. Hebei Med 15(4):381-383

101. Pang XD, Lin YG (2002) Observation of anti-inflammation of Chuandilong's in carrageenin-induced in mouse metatarsus. Tianjin J Tradit Chin Med 19(5):44-45

102. Du ZW, Pang XD (2003) Rhizoma Dioscoreae Nipponicae and its effect on arthroncus rates and pathologic changes in collagen-induced arthritis. Chin Rem Clin 3(6):471-473

103. Xie SJ, Song HR, Peng XR (2007) Experimental study on the pathologic effects of whole saponin of rhizoma Dioscoreae Nipponicae in adjuvant arthritis rats. J Sichuan Tradit Med 25(8):10-12

104. Cao YJ, Chen H, Yang G (2008) Study on antioxidation of dioscin in the subacute aging mice. Pharmacol Clin Chin Mater Med 24(3):19-20

105. Ma HY, Zhao ZT, Wang LJ (2002) Comparative study on anti-hypercholesterolemia activity of diosgenin and total saponin of Dioscorea panthaica. China J Chin Mater Med 27(7):528-530

106. Ma HY, Zhou QL, Wang BX (2002) Antagonistic effect of dx and diosgenin on hyperlipidemia induced by cholesterol in vivo and on blood platelet aggregation in vitro. China J Chin Mater Med 22(6):323-325

107. Wang QH, Chen RQ (2007) Effect of Dioscorea nipponica Makine (DNM) on thyroid hormone of rats with graves disease. Acta Chin Med Pharmacol 35(2):26-28

108. Wang QH, Chen RQ (2007) Gravse thyroid gland cells of rats' disease NIS mRNA expression and traditional Chinese medicine yam's impact on it. Chin Tradit Pat Med 29(11):1697-1698

109. Wang QH, Chen RQ, Fang JZ (2007) Gravse ultrastructural changes of thyroid tissue of rats' disease and yam to its effects. Liaoning J Tradit Chin Med 34(1):22-23

110. Ning KY, Li YK (2008) Effects on methyl protodioscin on in vivo thrombosis and blood viscosity in rats. Tradit Chin Drug Res Clin Pharmacol 19(1):3-5

111. Wang BX (1996) Modern pharmacology of Chinese medicine. Tianjin Science and Technology Press, Tianjin

112. Lou FY (2010) Research progress of Chinese medicine Dioscorea nipponica. China Pharm 13(7):1041-1043

113. Qiu HQ, Su M, Tian JZ (2011) The research progress of yam Chinese medicine treatment of rheumatism. Shandong Med J 51(11):115-116

114. Li CL, Tang YJ (2008) Compound yam 35 cases of clinical observation on treatment of knee osteoarthritis. Pract Clin J Integr Tradit Chin West Med 8(4):35

115. Li CB, Zhou RL (2009) Traditional Chinese medicine internal and external treatment clinical observation on treatment of 128 cases of knee arthritis. China Pract Med 4(8):171-172

116. Jiangsu Medical College (2001) The dictionary of chinese medicinal herb. Shanghai Science and Technology Press, Shanghai

117. Li KM, Chen YW, Zhang YW (2007) Isolation and Identification of Dioscin and Pseudoprodioscin from Di'ao Xinxuekang. China Pharm 18(30):2339-2341

118. Yu ZK, Zhang CQ, Xie FL (2001) The clinical observation on the treatment effect of Weiaoxinpian on coronary heart disease angina pectoris. Mod J Integr Chin Tradit West Med 10(16):1520-1530

119. Zhang B, Niu JH, Gao DW (1999) Effect of Weiaoxinpian on diabetic patients with TXB2, 6-Keto-PGFI alpha and blood rheology. Chin J Basic Med Tradit Chin Med 2(12):38-39

120. Liu QW, Tian JZ, Li M (1998) Study of composition, pharmacology and clinical application of Dioscorea nipponica Makino. Shandong J Tradit Chin Med 17(1):29-31

121. Wang XZ (2004) Clinical observation of Viauchin in the treatment of angina pectoris of coronary heart disease. Cent Plains Med J 31(5):36

122. Gao FL, Sun CE, Guo WH (1982) Yam clinical observation on treatment of 302 cases of chronic brucellosis. Ningxia Med Commun 1:65-68

123. Gao FL (1983) Yam efficacy analysis of the treatment of chronic brucellosis. Chin J Endemiol 2(2):125-126 
124. Han YC (1990) The observation of treatment of Yam on chronic brinell disease. Gansu Med J 9(3):190-192

125. Lei $L$ (2005) The clinical observation of Yam injection by acupuncture point injection treatment of severe bronchial asthma. J Emerg Tradit Chin Med 14(5):419

126. Sun XG, Zhang ZM (1990) The report about treatment of lipoma by Yam of 1 case. Shandong Med J 30(4):56

127. Zhu YQ, Zhou ZH, Li BC (2005) Research advance on the aqueous soluble active constituents of Dioscorea nipponica Makino. Yunnan Chem Technol 32(6):64-67

128. Liang XJ, Shang YZ, Song HR (2010) Acute toxicity study of whole saponin of rhizoma Dioscoreae Nipponicae in mice. J Chengde Med Coll 27(2):117-118
129. Zhou Q, Yao GT, Jin RM (2013) Preliminary study on hepatotoxicity induced by dioscin. Pharmacol Clin Chin Mater Med 29(2):29-32

130. Zhao CY, Chen DG, Zhao HT (2005) Analysis on market prospect and mixed benefit of Dioscoreae Nipponicae. Spec Econ Anim Plant 3:29

131. Xu L, An W (2011) The medicinal value of Yam and prospects of research and development in Xinzhou. Chin Countrys Well-off Technol 1(1):23-25

132. Sheng FG, He ZM, Chen K (2013) Research progress of the extraction separation, detection method and pharmacological action of the diosgenin. Lishizhen Med Mater Med Res 24(4):914-917

\section{Submit your manuscript to a SpringerOpen ${ }^{\circ}$ journal and benefit from:}

- Convenient online submission

- Rigorous peer review

- Open access: articles freely available online

- High visibility within the field

- Retaining the copyright to your article

Submit your next manuscript at $\boldsymbol{\nabla}$ springeropen.com 